\title{
AGUAS, RIEGO Y CULTIVOS: CAMBIOS Y PERMANENCIAS EN LOS aYllus de San Pedro de Atacama
}

\author{
Isabel Sepúlveda Rivera', Raúl Molina Otárola², María del Mar Delgado-Serrano y \\ José Emilio Guerrero Ginel ${ }^{4}$
}

\section{* Introducción}

Resumen

El agua ha sido vital en el desarrollo histórico en los ayllus de San Pedro de Atacama, regados por los ríos San Pedro y Vilama. Los aportes hídricos de estos ríos han venido disminuyendo desde la década de 1940 en adelante, lo que ha supuesto cambios sucesivos en las prácticas culturales de aprovechamiento y gestión del agua, a fin de mantener la seguridad del riego y sostener una agricultura basada en cultivos tradicionales - maíz, trigo, alfalfa - Este artículo constata, con estadísticas, la disminución constante de los caudales medios anuales de los ríos en los últimos setenta años, los cambios en el sistema e infraestructura de riego, y las sucesivas reorganizaciones para gestionar un recurso hídrico cada vez más escaso en un ambiente de desierto

extremo. Desvela que en los últimos cincuenta años la superficie regada y cultivada se redujo en casi un $50 \%$, en conjunto con el descenso de los aportes hídricos de los ríos San Pedro y Vilama. Constata que la estructura tradicional de cultivos se mantuvo hasta años recientes, $y$ se pregunta si el actual equilibrio precario entre aguas, riego y cultivos se puede sostener en el tiempo en los ayllus de Atacama.

Palabras claves: ríos San Pedro y Vilama - infraestructura de riego - cultivos tradicionales.

\begin{abstract}
Water has been an essential factor in the historical development of the Ayllus of San Pedro de Atacama, irrigated by the San Pedro and Vilama rivers. The amount of water carried by these rivers has been diminishing since the 1940s, which has forced successive changes in the cultural practices of water use and management in order to ensure irrigation and to sustain an agriculture based on traditional crops - maize, wheat and alfalfa. This article uses statistical data to demonstrate the ongoing reduction of the average yearly flow rate of these rivers over the last seventy years, changes in the irrigation system and infrastructure, and the successive organizational changes that have occurred to manage this scarce hydrological resource in a desert environment. The analysis reveals that over the last forty years the irrigated and cultivated surface area has reduced almost 50\%, paired with the reduction in the hydric contributions of the San Pedro and Vilama rivers. This article also showthat the traditional crop structure has been maintained until recent years and explores whether the present balance between water supply, irrigation and crops is sustainable over time in the Atacama's ayllus.
\end{abstract}

Abstract

Key words: San Pedro and Vilama rivers - irrigation infrastructure traditional crops.

Recibido: Mayo 2015. Aceptado: Octubre 2015
El agua ha adquirido relevancia en el debate contemporáneo a raíz de la discusión del cambio climático y la constatación de la disminución de las precipitaciones en muchas áreas del planeta, lo que tiene como efectos una reducción hídrica que precariza la sustentabilidad social y económica (CEPAL 1991; PNUMA 2000, 2014; Klare 2003; Yáñez y Molina 2011). Estos ciclos de disminución hídrica, en territorios de comunidades andinas donde las cuencas - en su mayoría - son alimentadas por glaciares y aguas subterráneas, repercute en la rápida disminución de estas fuentes (Thompson et al. 2006; Vuille 2013), y con ellas, los recursos hídricos de los que estas comunidades dependen para el pastoreo y la producción agrícola, entre otros usos de medios de vida.

Es pertinente estudiar la repercusión de la crisis hídrica en estos territorios desde el campo de la agroecología, puesto que en sus bases teóricas incorpora enfoques de multidisciplinariedad y complejidad que permiten entender el manejo del agua, del suelo, la producción de cultivos, la crianza de animales, el manejo de praderas naturales y especies forestales. Junto con lo productivo, considera los aspectos sociales y culturales, en un entramado de

1 Universidad de Córdoba, España. Wim Sonneveldstraat 9, 6708 NA, Wageningen, PAÍSES BAJOS. Email: isabelsepulv@ yahoo.com

2 Centro de Estudios del Hombre en Desierto CIHDE, Universidad de Tarapacá. Av. General Velásquez 1775, Arica, CHILE. Email: raulımolina@gmail.com

3 Departamento de Economía, Sociología y Política Agrarias, Campus Universitario de Rabanales, Universidad de Córdoba. Edificio Gregor Mendel, $3^{\text {a }}$ Planta, 14014 Córdoba, ESPAÑA. Email: mmdelgado@uco.es

4 Universidad de Córdoba, España. Avenida Medina Azahara 5, 14071 Córdoba, ESPAÑA. Email: pargugij@uco.es 
sinergias y relaciones sistémicas que explican los agroecosistemas andinos con todos sus componentes. (Rist y San Martín 1993; Altieri 1996; Sevilla 2011). De acuerdo con Altieri y Nicholls (2000), esta sinergia de multidisciplinariedad permite que los agrónomos comprendan los elementos socioculturales y económicos de los agroecosistemas, y a su vez, que los científicos sociales aprecien los elementos técnicos y ecológicos de estos.

Diversos estudios han investigado la variabilidad climática y su incidencia en la producción de las comunidades andinas, en especial su adaptación a una geografía compleja bajo un ambiente con drásticas restricciones agroclimáticas (Murra 1972; Núñez 1995). En tanto Fonseca y Mayer (1988), Altieri $(1985,1996)$ y Delgado (1992) rescatan las prácticas agrícolas tradicionales y tecnologías andinas, en el aporte al desarrollo de producción sostenible, Lucic (1997), Boelens et al. (2004) y Urteaga (2006) profundizan en la gestión colectiva del agua, en el pluralismo legal y las normas de derecho consuetudinario 5 . Valderrama y Escalante (1988) y Van Kessel (2000), explican el agua como fuente material, que constituye parte escencial de la identidad sociocultural en las comunidades andinas del norte de Chile, ya que les ha permitido mantener la sostenibilidad de los recursos naturales disponibles, lo que según Rivera (1995) puede considerarse como la forma más evidente de apropiación de su entorno sociogeográfico.

Hoy en día, estas características socioculturales del uso y manejo de los recursos hídricos son los argumentos fundamentales para oponerse a la imposición del derecho positivo y políticas neoliberales respecto del agua (Gentes 2005; Bebbington 2007), porque la imposición de estas políticas viene a acentuar las difíciles condiciones que enfrentan las comunidades andinas en el acceso, distribución y sostenibilidad de sus recursos hídricos.

5 Consultar los trabajos de investigación desarrollados en el marco del programa Water Law and Indigenous Rights (WALIR) sobre derechos indígenas y locales, relacionados con las legislaciones y políticas hídricas.

6 La información primaria de trabajo en campo, ha sido llevado a cabo por la primera autora, en el marco de la Tesis que realiza, apoyado además de la información personal, ya que ha trabajado más de quince años en la zona en temas agrícolas, y ha sido parte de la Asociación de Regantes como dirigenta y comunera.
El presente artículo analiza la situación del uso, disponibilidad y manejo del agua en los ayllus de San Pedro de Atacama, enclavados en el desierto y salar de Atacama en el norte de Chile, donde los aportes hídricos de los ríos San Pedro y Vilama han venido disminuyendo drásticamente desde la década de 1940, obligando a los regantes a efectuar cambios sucesivos en las prácticas culturales de aprovechamiento y gestión del agua, a fin de mantener la seguridad del riego y sostener dificultosamente una agricultura tradicional que, en los últimos cincuenta años, se ha visto mermada a casi la mitad de su superficie. Este artículo responde a interrogantes fundamentales: ¿Cuánto han disminuido en los últimos setenta años los caudales de los ríos San Pedro y Vilama)?, ¿qué impacto ha tenido en la disminución y permanencia de los cultivos tradicionales?, icuáles son los períodos de gestión del agua de riego que se pueden reconocer en los ayllus de San Pedro de Atacama?, y icómo los regantes han resisitido el estrés hídrico mediante la gestión del riego?

Bajo una perspectiva multidisciplinar, se conjuga la visión agronómica/técnica con un enfoque histórico y social del agua y de las organizaciones de regantes. Se realiza un análisis diacrónico en que se explican las variaciones que ha experimentado el sistema de riego en el tiempo, además de un análisis sincrónico mediante el cual se explican cuáles son los factores fundamentales que marcan cada uno de estos períodos evolutivos. Para ello se ha realizado una exhaustiva revisión de las estadísticas de caudales históricos de los ríos Vilama y San Pedro, y se han efectuado entrevistas semiestructuradas a agricultores, dirigentes y representantes de la institucionalidad pública y privada. Además, se ha realizado un extenso trabajo de campo ${ }^{6}$ sobre el levantamiento de los sistemas de riego, y gestión de los mismos, en los ayllus de San Pedro de Atacama.

El artículo se desarrolla en tres fases. La primera parte con un breve repaso de los estudios hídricos que se han realizado en la zona de San Pedro de Atacama; describe el funcionamiento del sistema de las cuencas de los ríos San Pedro y Vilama, y da cuenta de la sistemática disminución de los caudales de estos ríos. La segunda fase describe la forma en que se ha organizado el sistema de riego y los períodos que caracterizan la gestión del agua entre las décadas del sesenta y hasta el año 2014. La tercera fase describe la situación de la superficie cultivada y 
la disminución, extinción y permanencia de los cultivos tradicionales. Finalmente, se realizan reflexiones finales y se concluye con nuevas preguntas acerca de las relaciones entre el agua, el riego y los cultivos en los ayllus de San Pedro de Atacama.

El estudio de los ciclos de aridez en Atacama en los últimos quince mil años (Oschenius 1971, 1973, 1986; Weischet 1975; Nogami 1982) han sido de utilidad para comprender el poblamiento prehispánico, y especialmente para estudiar los desarrollos culturales desde el período Arcaico hasta el proceso de sedentarización e inicio de la actividad agrícola y ganadera en los ayllus de San Pedro de Atacama (Núñez 1992; Núñez y Dillehay 1992; Núñez et al. 1995). Para el período colonial, los estudios de complementariedad ecológica, poblamiento y movilidad indígena contienen algunas referencias a la agricultura en los ayllus de San Pedro de Atacama, a menudo describen y nombran los cultivos, pero no se detienen en las prácticas agrícolas y de los usos hídricos (Hidalgo 1984; Núñez 1992; Martínez 1998; Castro 2001). Para el siglo XIX, existen cortas narraciones de las economías agrícolas y de los cultivos en San Pedro de Atacama, las primeras realizadas por viajeros (Philippi 1860; Boman 1908; Bowman 1924; Von Tschudi 1966; Phillipi 1975; Dalance 1975[1851]) y las segundas aportadas por estudios recientes (Cajías 1975; Gundermann 2002; Barros 2008). En el siglo $X X$ comienzan a ser relevantes los estudios culturales del agua, el riego y los cultivos, cuyas primeras referencias se pueden encontrar en las etnografías realizadas en Peine y Socaire en la década de 1950 (Monsty et al. 1954; Munizaga 1958; Barthel 1986 [1957]). En la década del sesenta se conocen dos clásicos estudios efectuados por geógrafos (Aranda et al. 1964; Aranda 1968), que darán cuenta de los cambios que están ocurriendo en el manejo y gestión del agua de riego en los ayllus de San Pedro de Atacama. Estos aportes coinciden con las líneas temáticas de investigación, centradas en torno a las "sociedades hidráulicas" y las investigaciones sobre la agricultura andina en las décadas de 1960 y 1970 (Palerm 2004). Los estudios culturales del agua, el riego y las comunidades agrícolas andinas no decayeron en la década de los ochenta, lo que estimuló nuevas investigaciones antropológicas, geográficas y agronómicas (Mitchell 1981; Ortloff 1981). En la década de los noventa, el tema agrario en territorios andinos sigue vigente, la revista Allpanchis del Cusco dedica dos volúmenes (27 y 28 ,
1996) a discutir la antigüedad y actualidad del riego en los Andes. En el área del salar de Atacama se publican estudios que destacan el valor cultural, histórico, económico y productivo del agua en las comunidades atacameñas (Gundermann y González 1995; Lehnert 1995; Pourrut y Núñez 1995; Rivera 1995; Cuadra 2000). Estos aportes, aunque algunos trascienden el área de los ayllus, aportan reflexiones e ideas que caracterizan la situación hídrica, de los cultivos y del riego en Atacama.

La relevancia de continuar discutiendo el tema del agua, el riego y los cultivos en los ayllus de San Pedro de Atacama parte de la constatación de la disminución de aproximadamente un 50\% de los caudales de los ríos San Pedro y Vilama en los últimos setenta años. Esta carestía hídrica ha obligado a implementar nuevas técnicas e ingenierías de riego, que han provocado cambios en la organización social del manejo del agua y de la infraestructura de riego. Estos cambios van acompañados de una complejización del sistema de riego a lo largo de los últimos cincuenta años, asociada a la fragmentación de la propiedad de la tierra, que aumentó el número de regantes y de turnos.

\section{Los ayllus y los ríos San Pedro y Vilama}

Los ayllus de San Pedro de Atacama se encuentran localizados a $2450 \mathrm{msnm}$, en el costado norte del salar de Atacama, donde reciben los aportes hídricos de los ríos San Pedro y Vilama. Estos ríos y las aguas subterráneas han dado origen a formaciones boscosas de chañar (Geoffroea decorticans), tamarugos (Prosopis tamarugo) y algarrobo (Prosopis chilensis). En la actualidad se contabilizan veinte ayllus: Cuchabrache, Suchor, Bellavista, Guachar, Tambillo, Catarpe, Quitor, Conde Duque, Solcor, Yaye, Larache, Checar, Séquitor, Coyo, Tulor, Vilama, Solor, Cúcuter, Poconche y Beter, distribuidos a lo largo de 14 kilómetros entre Cuchabrache y Tulor? (ver Figura 1).

7 La localidad de Alana a veces se considera ayllu, pero tradicionalmente ha formado parte de Solor. Quedó separada de este por la construcción del camino entre San Pedro de Atacama y Toconao. También, a veces, se nombra como ayllu a Guatín, pero es más bien una estancia. 


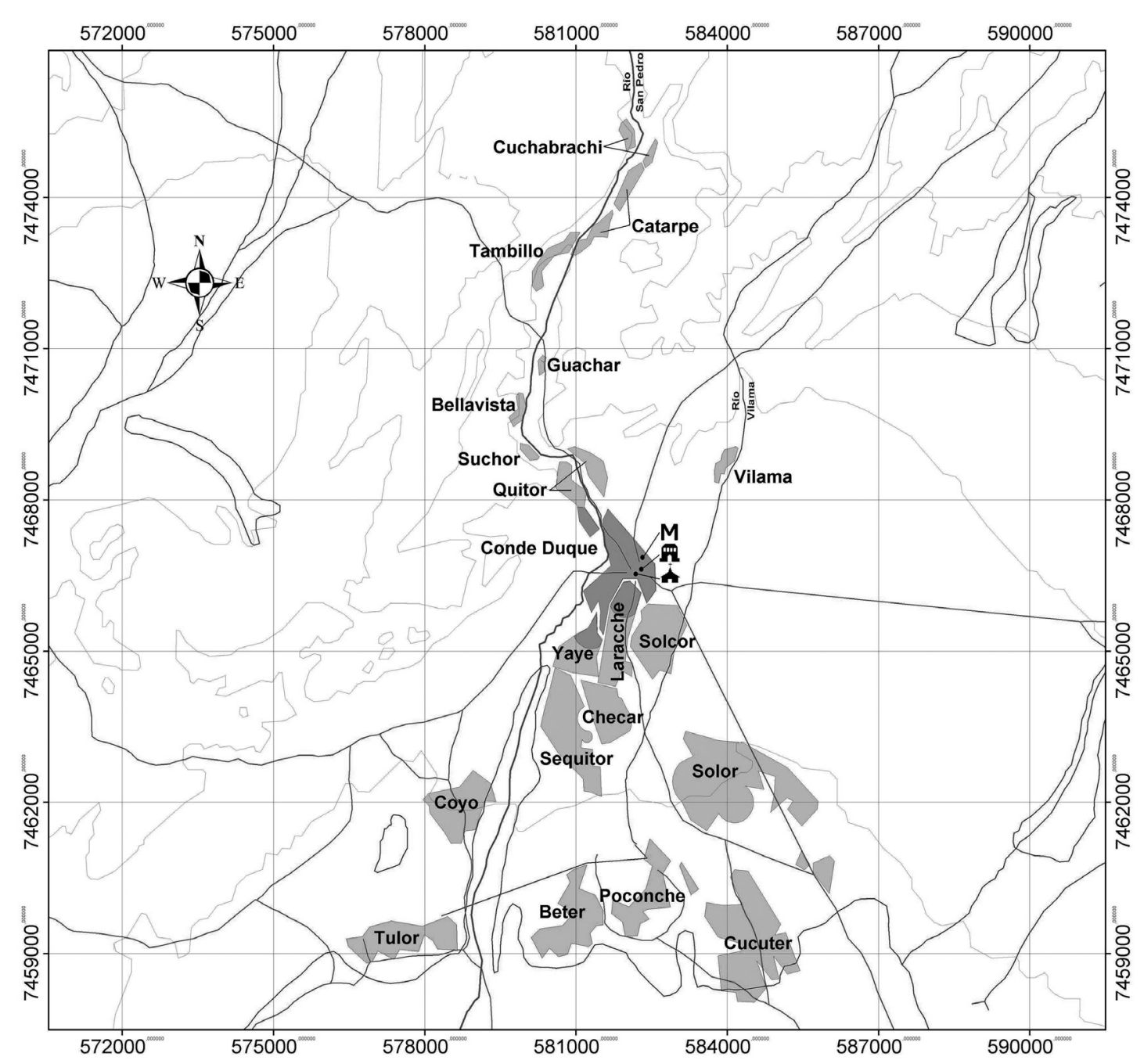

Figura 1. Croquis San Pedro de Atacama y sus ayllus.

Los ayllus de San Pedro de Atacama, denominados así por ser tradicionalmente unidades socioterritoriales de familias, se caracterizan por ser agrupaciones de tierras aisladas con bosques, que en su interior contienen estructuras prediales en las que se practican la agricultura bajo riego. Estas "islas" de bosques y tierras fértiles, son pequeños oasis rodeados de tierras de desierto. Cada unidad territorial puede contener uno o más ayllus que estuvieron ocupados, y en la mayoría de los casos lo siguen estando, por linajes y relaciones de parentesco entre familias atacameñas que han heredado las tierras de sus ancestros o las han adquirido personas de otros pueblos del salary de la puna. También en los ayllus se ha asentado población procedente de otros lugares de Chile o del extranjero, proceso que ocurre desde mediados del siglo XX (Rivera 1995). Actualmente, el traspaso de la propiedad y los cambios del uso del suelo agrícola a residencial se han agudizado por la expansión de la industria del turismo y por los usos residenciales (Bolados 2014). Sin embargo, la mayor parte de los propietarios de tierras siguen cultivando las especies tradicionales y realizando el riego con las aguas provenientes de los ríos San Pedro y Vilama.

El río San Pedro nace por encima de los $4000 \mathrm{msnm}$. El curso inicial es el Ojo Putana, una vertiente que emerge a 
los pies del volcán Putana, de 5890 msnm. Más abajo, el río Putana recibe aguas del pequeño río Incahuasi, para luego tener como tributario al río Jauna, que nace en una hondonada de la puna. De allí baja encajonado hasta la localidad de Río Grande, a 3200 msnm, y aguas abajo recibe al río Salado o Chuschul, donde toma el nombre de río San Pedro. El cauce natural ingresa por el costado poniente de los ayllus en Cuchabrache-Catarpe, atraviesa Quitor, y continúa en dirección sur, bordeando a los ayllus de Conde Duque, Yaye y Séquitor, hasta llegar a los ayllus de Coyo y Beter, para después verter las aguas en el salar de Atacama. El agua de riego se capta en el ayllu de Cuchabrache, en la cabecera de entrada norte a la localidad de San Pedro, desde donde se inicia una extensa canalización que conduce las aguas hacia los ayllus de Tambillo, Suchor, Guachar, Bellavista, Catarpe, Quitor, Conde Duque, Solcor, Larache, Checar, Yaye, Séquitor, Coyo, Solor y Cúcuter. Las características de estas aguas permiten la producción de cultivos y frutales adaptados o resistentes a sus condiciones, como maíz, trigo, alfalfa, perales, membrillos, uvas y diversas hortalizas, pues tienen valores químicos de $2,5 \mathrm{mg} / \mathrm{L}$ de boro y o,13 $\mathrm{mg} / \mathrm{L}$ de arsénico, además tiene $2,2 \mathrm{mmhos} / \mathrm{cm}$ de conductividad eléctrica y un $\mathrm{pH}$ cercano a 8 , que tienden a aumentar en el período de verano. No obstante la salinidad de esta agua, provocada preferentemente por los aportes del río Salado, ellas han regado históricamente las tierras atacameñas.

El río Vilama ingresa por la parte oriental de San Pedro de Atacama. Se forma de vertientes termales salobres en la quebrada de Turipite a los $3685 \mathrm{msnm}$, y aguas abajo, en el sector de Guatín, recibe como afluente al río Purifica, que nace a los $3590 \mathrm{msnm}$ en las faldas del volcán Sairecabur. El cauce natural del río Vilama entregaba sus aguas al llano de Vilama, pero actualmente el río corre encauzado en canales que riegan los ayllus de Vilama, Poconche, Beter y Tulor. Sus aguas son altamente salinas, con índices de $2,9 \mathrm{mmhos} / \mathrm{cm}$ de conductividad eléctrica, un $\mathrm{pH}$ de 8 y o,625 mg/L de Arsénico ${ }^{8}$, que sobrepasan en más de cinco veces la norma chilena para aguas de regadío. Sin embargo, el alto contenido de boro, con concentraciones de 17 $\mathrm{mg} / \mathrm{L}$ - cuyo máximo para riego no debería sobrepasar los 0,75 mg/L-, es el elemento que más condiciona los cultivos, especialmente frutales, en los ayllus de Vilama, Poconche, Beter y Tulor.

\section{Disminución de los recursos hídricos}

A la limitante de calidad de las aguas de los ríos San Pedro y Vilama se suma la constante disminución de los caudales hídricos en los últimos setenta años (1940-2013). Para comprender esta reducción se debe tener presente que los caudales están regulados por las precipitaciones que ocurren en la puna por sobre los $4000 \mathrm{msnm}$, donde nacen ambos ríos. Según Pourrut y Covarrubias (1995), la principal fuente proviene de los deshielos de las altas cumbres de la cordillera de los Andes, lo que ha dado origen a grandes reservorios de aguas subterráneas que, en un tiempo de lenta escorrentía, alimentarían el sistema de estas cuencas. Allí, el invierno boliviano o altiplánico aporta precipitaciones traídas por el ciclón amazónico (Ochsenius 1986). En ocasiones, las cuencas de los ríos Vilama y San Pedro reciben aportes de invierno-primavera provenientes del océano Pacífico (Kalin et al. 1997), que corresponden a masas de aire polar frío aislado (cuttoffs) que se trasladan en altura en zonas de baja latitud (Núñez et al. 1995-96). Estos flujos chocan con el aire cálido/húmedo y gatillan precipitaciones durante el invierno, primavera y otoño (Fuenzalida y Rutland 1986). Sin embargo, los mayores aportes de precipitaciones son de verano y corresponden a "un porcentaje variable entre el 80 y $50 \%$ del total de precipitaciones del área" (Romero et al. 1997: 89). Las precipitaciones pueden ser de nieves que ocurren preferentemente por sobre los 4000 a 5000 $\mathrm{msnm}$. Bajo estas alturas, las precipitaciones líquidas o lluvias son más frecuentes, pero disminuyen sus montos a medida que se baja en altura y se alejan de la cordillera hacia el poniente. Las cumbres de los altos volcanes sobre los $6000 \mathrm{msnm}$, entre el Licancabur y el Tocorpuri, reciben precipitaciones sólidas, estimadas en $360 \mathrm{~mm}$ anuales, aunque las superficies de recepción de los conos son pequeñas (Oyarzun 2002). A los 4000 msnm, en la zona de puna o altiplano de las cuencas de los ríos San Pedro y Vilama, las superficies son más extensas. En esta zona el promedio calculado de las precipitaciones

8 Entre los años 1990 y 2000 , científicos de la Universidad de Berkeley, California, a cargo del doctor Allan Smith, investigaron la concentración de arsénico en el agua de los ríos San Pedro y Vilama, y las concentraciones de este elemento en la población. Los resultados de altas concentraciones de sales en las aguas favorecieron la instalación de la planta abatidora de arsénico que existe actualmente en San Pedro de Atacama. 
sería de $200 \mathrm{~mm}$ anuales (Salazar et al. 2003), aunque Alonso (1997) las calcula en 200-250 mm anuales. Sin embargo, estas estimaciones están sobredimensionadas, puesto que la única estación meteorológica en el altiplano cercana a la cuenca alta de los ríos San Pedro y Vilama es la del Tatio, y ha registrado un promedio interanual de $137,5 \mathrm{~mm}$ de precipitaciones en los últimos treinta $y$ siete años (1978-2014) $)^{9}$. Descendiendo de los cuatro mil metros, las precipitaciones bajan drásticamente, pues en San Pedro de Atacama (2450 msnm) éstas no superaron los $22,9 \mathrm{~mm}$ anuales de promedio entre los años 1960 y 2011 (Arrau Ing. 2014). En virtud de lo expresado, se puede comprender que el escurrimiento de los ríos San Pedro y Vilama depende de las precipitaciones que ocurren por sobre los $4000 \mathrm{msnm}$, puesto que sus caudales se crean a partir de los aportes de reservorios de aguas subterráneas y subsuperficiales de la zona alta de la cuenca (Pourrut y Covarrubias 1995; Bevacqua 2005; Salas y Luna 2013). Se estima que la recarga del sistema hidrológico que riega los ayllus de San Pedro de Atacama corresponde en un $17 \%$ a aguas superficiales y un $83 \%$ a aguas subterráneas (Muñoz y Ortiz 2004).

La distribución de las precipitaciones durante el año, especialmente los aportes del invierno altiplánico, estaría influyendo en el comportamiento de los caudales de los ríos San Pedro y Vilama durante los meses de verano. Un estudio de Oyarzún (2002) muestra que el río San Pe- dro alcanza su mayor caudal en los meses de febrero a marzo, épocas de lluvias altiplánicas, para luego descender drásticamente entre abril y mayo. De allí se recupera levemente para mantener su caudal, y en el mes de noviembre disminuye al mínimo. En diciembre comienza a incrementarse el escurrimiento hídrico. El río Vilama, a su vez, muestra un comportamiento similar en sus caudales a lo largo del año. Por tanto, la mayor demanda de riego en los ayllus, entre los meses de diciembre a marzo, cuenta siempre con el ascenso del caudal, pero las aguas de las repentinas crecidas también producen un aumento de sales y sedimentos, que obliga a los regantes a devolverlas al cauce natural para evitar daños a los cultivos y a los terrenos. De allí que estas crecidas, a veces, generen un déficit hídrico en los cultivos, durante los meses claves de su período vegetativo ${ }^{10}$.

Aunque no se conocen estadísticas de precipitaciones para el altiplano antes de 1978 (estación El Tatio), se postula que la disminución de los caudales de los ríos San Pedro y Vilama de los últimos setenta años estaría asociada a una disminución de las precipitaciones en las cuencas hídricas de estos ríos, atribuible a un cambio climático asociado a una reducción de los aportes de humedad procedentes de la Amazonía (Ortlieb 1995). Las causas serían climáticas en la medida en que en ambas cuencas no existen extracciones de aguas subterráneas o superficiales por empresas mineras o industriales. La

9 El promedio de precipitaciones en el Tatio ha sido calculado con los datos de los años 1978 a 2014, descontando el año 2006 que no tiene registros de precipitaciones. Los registros de la Estación Meteorológica El Tatio son los siguientes:

\begin{tabular}{|c|c|c|c|c|c|c|c|c|c|}
\hline $\begin{array}{c}\text { El Tatio } \\
\text { Año }\end{array}$ & Pp.en mm. & Año & Pp.en mm. & Año & Pp.en mm. & Año & Pp.en mm. & Año & Pp.en mm. \\
\hline 1978 & 98 & 1986 & 187 & 1994 & 116,6 & 2002 & 71,5 & 2010 & 8,8 \\
\hline 1979 & 142,9 & 1987 & 282,9 & 1995 & 180,5 & 2003 & 36 & 2011 & 207 \\
\hline 1980 & 55,7 & 1988 & 75,7 & 1996 & 20,5 & 2004 & 6,8 & 2012 & 352,7 \\
\hline 1981 & 126,1 & 1989 & 132,7 & 1997 & 186,6 & 2005 & 110,2 & 2013 & 94,2 \\
\hline 1982 & 57,8 & 1990 & 128,3 & 1998 & 79,9 & 2006 & $s / r$ & 2014 & 63,4 \\
\hline 1983 & 152 & 1991 & 82,4 & 1999 & 243 & 2007 & 53,4 & & \\
\hline 1984 & 341,5 & 1992 & 45 & 2000 & 244,7 & 2008 & 123,1 & & \\
\hline 1985 & 259,5 & 1993 & 124,1 & 2001 & 421,7 & 2009 & 36,7 & & \\
\hline
\end{tabular}

Fuente: Estación El Tatio. Dirección General de Aguas. Ministerio de Obras Públicas.

10 Las aguas del río Salado, afluente del río San Pedro, arrastran en su curso sales de formaciones geológicas marinas. Los aportes salinos aumentan con las crecidas del verano. Los regantes del río San Pedro han pedido una solución desde al menos la década del noventa. En sesión No 60 del año 2011, la Comisión Nacional de Riego, CNR, acordó ejecutar el estudio en que se proyecta construir un embalse de control de crecidas, pero la obra aún esta cómo proyecto. 
disminución de los caudales de ambos ríos, aproximadamente a la mitad en las últimas siete décadas (Tabla 1 y Figura 2), ha reducido la disponibilidad de aguas de riego, y a pesar de las ostensibles bajas en las superficies cultivadas, ha obligado a cambiar la gestión social y técnica del agua para mantener la continuidad del sistema agrícola de San Pedro de Atacama.

Las estadísticas de caudales, desde el año 1940 al 2013, muestran una disminución de las aguas de riego. En el río San Pedro, el descenso de un 44\% del caudal promedio anual en casi en los últimos setenta años se verifica en las cifras, puesto que el caudal medio bajo de 1,127 $1 / \mathrm{s}$ en la década de 1940 , a un promedio de $630 \mathrm{l} / \mathrm{s}$ en la primera década del 2000. En el caso del río Vilama, por poseer una cuenca más pequeña y más baja, el descenso del caudal es aún más drástico. De las cifras disponibles, se aprecia que el caudal promedio anual, de $332 \mathrm{l} / \mathrm{s}$ en la década del cuarenta, bajó a 134,5 1/s en la década del 2000 , equivalente a una disminución del 59,5\%. Pero ha seguido bajando, pues entre los años 2011 y 2014 el caudal promedio anual fue de $76,7 \mathrm{l} / \mathrm{s}$, es decir, una disminución de casi el $77 \%$ de caudal promedio en los últimos setenta años.

Las estadísticas de reducción de los caudales para agua de riego son confirmadas por la percepción y conocimiento de los atacameños. Los relatos argumentan que hubo una época en que disponían de mucha agua para regar las tierras, a lo que se asocian las buenas cosechas: “... Con tanta agua que venía, el maíz crecía lindo, el Capia y el Morocho y otro cortito que traían semilla de Camar... harto pasto había y animales, hasta parritas (vides) teníamos" (Marta Cervantes, regante del ayllu de Conde Duque, 2010). A su vez, Mirta Solís (2010), representando a la Asociación de Regantes del Río San Pedro, en cono-

\begin{tabular}{|c|c|c|c|c|c|c|c|c|}
\hline Año & $\begin{array}{c}\text { Río } \\
\text { San Pedro }\end{array}$ & $\begin{array}{c}\text { Río } \\
\text { Vilama }\end{array}$ & Año & $\begin{array}{c}\text { Río San } \\
\text { Pedro }\end{array}$ & Río Vilama & Año & Río San Pedro & Río Vilama \\
\hline 1940 & 1.010 & 450 & 1969 & 830 & 220 & 1994 & 628 & 150 \\
\hline 1947 & 1.208 & 300 & 1970 & 853 & 250 & 1995 & 528 & 160 \\
\hline 1948 & 1.087 & 301 & 1971 & 890 & -- & 1996 & 641 & 110 \\
\hline 1949 & 1.206 & 280 & 1972 & 810 & 240 & 1997 & 741 & 90 \\
\hline 1950 & 1.280 & 270 & 1975 & 790 & -- & 1998 & 611 & 130 \\
\hline 1951 & 1.350 & 370 & 1976 & 831 & 216 & 1999 & 675 & 100 \\
\hline 1952 & 945 & 370 & 1977 & 788 & 220 & 2000 & 595 & 100 \\
\hline 1953 & 1.914 & 520 & 1978 & 688 & 270 & 2001 & 692 & 130 \\
\hline 1954 & 1.280 & 300 & 1979 & 690 & 220 & 2002 & 735 & 140 \\
\hline 1955 & 1.450 & 340 & 1980 & 740 & 230 & 2003 & 653 & 130 \\
\hline 1956 & 1.128 & 270 & 1981 & 760 & 230 & 2004 & 660 & 170 \\
\hline 1957 & 990 & 280 & 1982 & 700 & 210 & 2005 & 581 & 200 \\
\hline 1958 & 723 & 260 & 1983 & 825 & 200 & 2006 & 597 & 110 \\
\hline 1959 & 1.000 & 360 & 1984 & 830 & 190 & 2007 & 658 & 130 \\
\hline 1960 & 1.110 & 360 & 1985 & 730 & 180 & 2008 & 613 & 110 \\
\hline 1961 & 1.039 & 340 & 1986 & 742 & 170 & 2009 & 520 & 140 \\
\hline 1962 & 995 & 280 & 1987 & 769 & 180 & 2010 & 626 & 120 \\
\hline 1963 & 831 & 240 & 1988 & 674 & 200 & 2011 & 581 & 70 \\
\hline 1964 & 809 & 230 & 1989 & 777 & 200 & 2012 & -- & 80 \\
\hline 1965 & 776 & 240 & 1990 & 674 & 190 & 2013 & 646 & 67 \\
\hline 1966 & 785 & 240 & 1991 & 636 & 170 & 2014 & - & 90 \\
\hline 1967 & 896 & - & 1992 & 680 & 170 & & & \\
\hline 1968 & 851 & - & 1993 & 624 & 150 & & & \\
\hline
\end{tabular}

Tabla 1. Caudales medios anuales río San Pedro y río Vilama (1940 a 2014).

Fuente: elaborado según base de datos de la Dirección General de Aguas DGA, y complementado con estadística de los estudios: Consorcio Geofun-Procivil 2000 (años 1940, 1972, 1975, 1977, 1951, 1984, 1955, 1985), Oyarzún 2002 (río Vilama entre los años 1947 y 1970). 


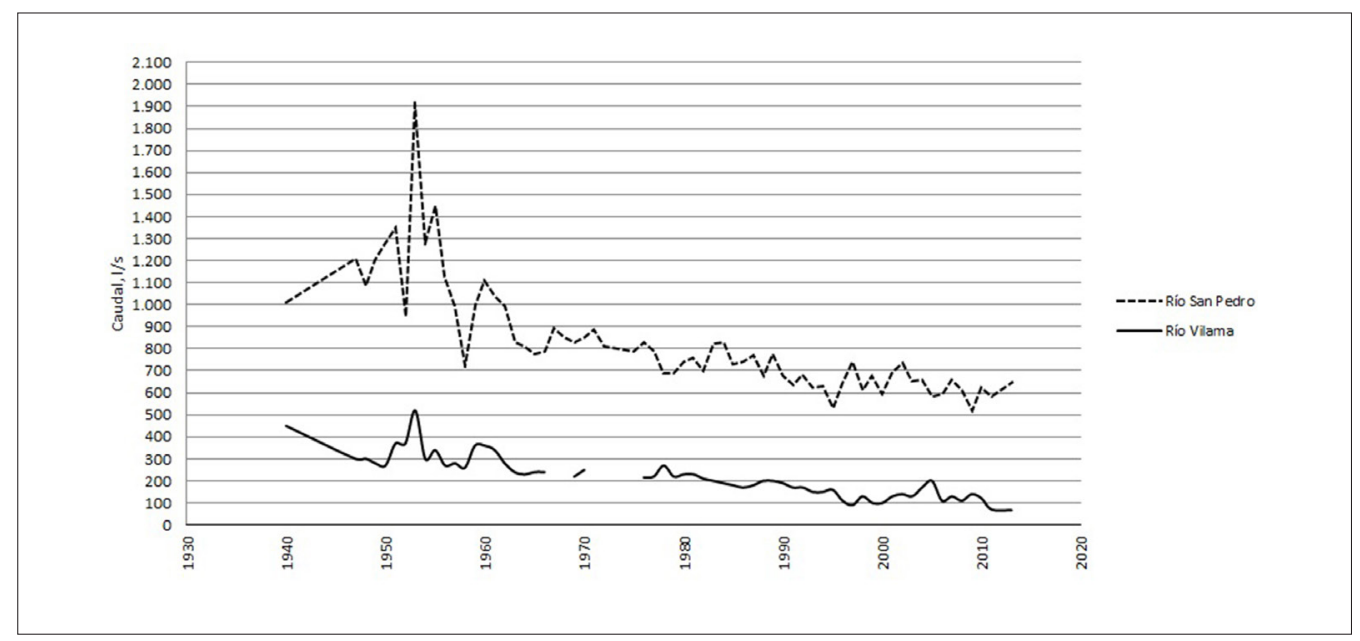

Figura 2. Disminución de los caudales de los ríos San Pedro y Vilama (1940-2014).

Fuente: elaborado en base de datos DGA, Geofun-Procivil 2000, Oyarzún 2002.

cimiento de las cifras de caudales, en 2006 señala: “... falta de agua de regadío, que en los últimos veinte años ha disminuido en más de un 50\%. O sea que de 1000 $1 / \mathrm{s}$ estamos hoy en día regando con menos de $500 \mathrm{l} / \mathrm{s}^{\prime \prime 11}$.

Esta disminución de la disponibilidad de aguas de riego ha ido acompañada, a partir 1964, de cambios en los sistemas e infraestructura de riego, destinados a aumentar la seguridad y la eficiencia del riego en los ayllus de San Pedro de Atacama, manejando las aguas cada vez más escasas para mantener un equilibrio con la estructura de cultivos y uso del suelo tradicional, a pesar de la constante disminución de la tierra cultivada.

\section{Cambios en la organización del agua e infraestruc- tura de riego}

La disminución de los caudales de los ríos San Pedro y Vilama ha generado, desde la segunda mitad del siglo $\mathrm{XX}$, reiteradas transformaciones en el sistema de aprovechamiento tradicional de las aguas para riego. Uno de los objetivos ha sido acortar los turnos de agua, para dar continuidad a la actividad agrícola y ganadera en los predios de los ayllus. Estas transformaciones están condicionadas histórica, social y ambientalmente por la reducción

11 Carta de la Asociación de Regantes y Agricultores del Río San Pedro, entregada por la presidenta Mirta Solís a la Presidenta de la República, Michelle Bachelet, el 10 de noviembre de 2006 en su visita a la localidad de San Pedro de Atacama. de los caudales de los ríos, por los cambios en la tenencia y fragmentación de las tierras y por factores económicos sociales relacionados con el empleo de la mano de obra.

Es necesario decir que la historia del riego en los ayllus de Atacama ha estado asociada al desarrollo cultural atacameño desde períodos prehispánicos. Los primeros canales pudieron ser de desagüe, técnica ya introducida a partir del 1200-400 AC en el período Formativo.

Estas infraestructuras se construyeron y funcionaron en base a la organización comunal (Santoro et al. 1998). Los cambios en el período inca y en los siglos coloniales debieron ser importantes, debido a la probable implementación de nuevas técnicas de riego y a la introducción de nuevos cultivos como el trigo y la alfalfa, que pudo haber significado la ampliación de la superficie y producción agrícola en los ayllus (Núñez 1995). Un nuevo proceso de expansión y aumento de los cultivos pudo ocurrir en San Pedro de Atacama a fines del siglo XIX y durante las primeras décadas del siglo XX, cuando los ayllus se transformaron en lugares de pastaje y engorda de los arreos de vacunos, traídos desde el noroeste argentino y llevados con destino a las salitreras (Denis 1987 [1920]). Esto implicó alimentar unas 30 mil cabezas de ganado al año (Aranda 1968). Concluido el ciclo de arrieraje, en la década de 1960 se produce, probablemente, una disminución de la superficie sembrada, y efectivamente, un cambio en el sistema de regadío, que vino a remplazar el reglamento de riego del año 1895. Los cambios en el riego fueron ca- 
tapultados por la disminución del agua, las pérdidas por infiltración y el distanciamiento en los turnos de riego. Esto obligó a una reingeniería de los canales, lo que cambió la distribución territorial de las aguas, los turnos y la organización social del riego (Aranda et al. 1964).

Desde 1960 hasta la actualidad, se reconocen a lo menos cuatro cambios en la organización e infraestructura del sistema de riego, que ocurren en los años 1964, 1995, 2005 y 2008. Estos cambios comprenden la infraestructura de canales, bocatomas y tranques, el reordenamiento de los turnos de riego y la introducción de nuevas técnicas de regadío, cambios que según Núñez (1995) han ocurrido manteniendo los aspectos más gruesos de las obras primarias de ingeniería ancestral. Además, estas modificaciones han generado cambios socio organizacionales, permitiendo a su vez mantener una estructura de cultivos tradicionales asociada a la subsistencia, y algunas prácticas culturales y festivas atacameñas, como se describe a continuación.

\section{"Regábamos con todo el río": el riego antes de 1960}

Antes de los cambios en el sistema de riego, ocurridos en 1964, los canales estaban cavados en tierras arcilloarenosas, lo que provocaba importantes pérdidas por infiltración. Las aguas de los ríos San Pedro y Vilama se mezclaban, y los atacameños regaban "con todo el río", o sea, sumando el caudal de ambos ríos, como señalan los antiguos habitantes de los ayllus. Los extensos canales requerían del buen funcionamiento, siendo de relevancia las tareas de "limpias de canal" para evitar obstrucciones y derrames de aguas (Aranda 1964; Rivera 1995). En esta organización única de riego, la máxima autoridad era el Juez de Aguas, un cargo de elección comunitaria desde largo tiempo entre los atacameños (Hidalgo 1992).

Las aguas del río San Pedro se vaciaban en el ayllu de Cuchabrache a un canal matriz. A la entrada del pueblo, este canal se separaba en dos. Uno iba en dirección al este, se dirigía atravesando Conde Duque, al “...sector occidental del Ayllu de Solcor y Tolanche donde se le unían las aguas del río Vilama. Después seguía hacia el extremo sur-occidental del Ayllo de Solcor y finalmente pasaba por el Ayllu de Cúcuter", existiendo canales intermedios que regaban "hasta la parte sur del pueblo de San Pedro y hasta los Ayllos de Chécar, Séquitor e incluso Larache".
El otro canal de la bifurcación mencionado seguía en dirección sur, pasando por los ayllus de Larache, Yaye, Séquitor, Coyo y Tulor: "En Tulor giraba ya con muy poca agua hacia el oriente para morir en las arenas del Ayllo de Béter, hasta Poconche" (Rivera 1995: 71).

La distribución del agua de riego se hacía por el canal matriz, dos canales principales, 12 bocatomas y otros ocho canales derivados que distribuían el agua hasta los predios. Allí, el riego era por sistema de inundación de pretiles, cuya altura estaba sobre el medio metro, formando una piscina que acumulaba el agua para infiltración, riego que debía durar de 35 a 40 días (Aranda et al. 1968). El sistema de riego comenzaba en el ayllu de Cuchabrache y terminaba en Poconche, para luego volver al mismo ciclo. El uso del riego con todas las aguas del río o de los ríos implicaba contar con importantes caudales, que entre los años 1940 y 1960 alcanzaba un caudal medio anual de 1,179 l/s en el río San Pedro, y de 335,4 l/s en el río Vilama (ver Tabla 1).

\section{Reingeniería de canales y cambios en el riego: 1964}

A partir de 1960, el Estado de Chile comenzó los estudios para modernizar el riego en los ayllus de San Pedro de Atacama. Lo hizo a través del diseño de ingeniería hidráulica, con lo cual se uniformó el riego "a los patrones vigentes en las Asociaciones de Canalistas del resto del país" (Rivera 1995: 73). El nuevo diseño consideró la construcción de 15 canales principales revestidos de cemento, para reducir las pérdidas de agua por infiltraciones (Aranda 1968). El nuevo diseño de riego vino a amortiguar, sin haberlo previsto, la caída en los caudales de ambos ríos San Pedro y Vilama, puesto que en el período comprendido entre 1961 y 1995, el caudal promedio del río San Pedro bajó a 772 1/s, y el del río Vilama descendió a 213 l/s (ver Tabla 1).

En 1964 las aguas de los ríos San Pedro y Vilama fueron separadas y destinadas a regar ayllus distintos. Las aguas del río San Pedro, bajas en boro y de mejor calidad, comenzaron a regar los ayllus desde Cuchabrache-Catarpe hasta Cúcuter. Para la distribución del agua se formaron siete grupos de riego, que agruparon ayllus por unidades territoriales: grupo $\mathrm{N}^{\circ}$ : Cuchabrache, Tambillo, Suchor, Guachar y Quitor; grupo $\mathrm{N}^{\circ} 2$ : Conde Duque (una parte), Yaye y Checar; grupo $\mathrm{N}^{\circ}$ : Conde Duque (una parte), La- 
rache y Solcor; grupo $\mathrm{N}^{\circ} 4$ : Séquitor y Coyo; grupo $\mathrm{N}^{\circ} 5$ : Solor; grupo $\mathrm{N}^{\circ} 6$ : Cúcuter; y grupo $\mathrm{N}^{\circ} 7$ : Conde Duque (Estanque). Las aguas del río Vilama, en cambio, se destinaron a regar los ayllus de Vilama, Poconche, Beter y Tulor. En la nueva ingeniería estos ayllus fueron "sacrificados" al entregarles aguas con abundancia de boro, que limitó los cultivos a prácticamente alfalfa, algo de maíz y a especies silvícolas nativas de chañar y algarrobos, especies ya adaptadas a estas condiciones químicas del agua. En cambio, en los ayllus regados por las aguas del río San Pedro, con niveles más bajos de boro, continuaron los cultivos de trigo, frutales, maíz, hortalizas y alfalfa. El nuevo diseño de la red de canales supuso cambios en los turnos de riego, pues descendieron de los 35 a 40 días antes de 1964, a 20 o 25 días con los nuevos canales. Junto a ello, la antigua organización, la Junta de Regantes de San Pedro de Atacama, se reemplazó por dos nuevas organizaciones: la Junta de Regantes del río San Pedro y la del río Vilama.

\section{Inscripción de aguas comunitarias y los costos del riego (1995-2005)}

El sistema anterior funcionó con pocos cambios desde 1964 hasta 1995. En este último año se produce la inscripción de los derechos comunitarios de aprovechamiento de las aguas de los ríos San Pedro y Vilama. A su vez, en este período se inicia el diseño de nuevas obras complementarias de riego, teniendo presente la disminución histórica de los caudales de los ríos, que entre 1996 y 2005 habían descendido notablemente; el río San Pedro a $658 \mathrm{l} / \mathrm{s}$ y el Vilama a $130 \mathrm{l} / \mathrm{s}$ (ver Tabla 1).

La inscripción de los derechos de aguas dio origen a nuevas organizaciones de riego, que si bien en lo formal reemplazaron a las constituidas en 1964, en su estructura operativa mantuvo a los siete grupos de regantes conformados desde esa época. Las nuevas organizaciones pasaron a llamarse Asociación de Regantes y Agricultores de San Pedro de Atacama y Asociación Atacameña de Regantes del Río Vilama, las que inscriben respectivamente derechos por 1157 l/s en el río San Pedro y 221 l/s en el río Vilama (Barros 2009). Las inscripciones de derechos se hacen sobre el caudal máximo histórico, aquel de la década de 1950, para asegurar a los atacameños derechos sobre el conjunto del caudal y prever variaciones futuras. Estas inscripciones de derechos de aguas se efectúan con pertinencia indígena, desechando los atacameños lo establecido en el Código de Aguas de $1981^{12}$, que propiciaba la inscripción de derechos individuales con una lógica de mercado que separaba el agua de la tierra.

Los regantes del río San Pedro y Vilama conocían los efectos que había tenido la aplicación del Código de Aguas en las comunidades del río Loa, las que habían visto drásticamente reducidos sus derechos de aprovechamiento de aguas para riego (Yañez y Molina 2008). Por tanto, los miembros de las asociaciones de regantes de San Pedro deciden mantener sus sistemas y derechos de riego comunitarios, acogiéndose para su inscripción a la Ley Indígena 19.253 de 1993. Esta ley, en su artículo $3^{\circ}$, señala que las aguas son de propiedad ancestral de las comunidades indígenas, y en el artículo $64^{\circ}$, obliga a los organismos del Estado a proteger las aguas de comunidades atacameñas, prohibiendo la entrega de nuevos derechos sobre las aguas aprovechadas por estas comunidades indígenas. La inscripción de aguas ancestrales y comunitarias fue posible gracias a que los dirigentes atacameños rechazaron, en el año 1991, los intentos de la Dirección General de Aguas (DGA) de aplicar el Código de Aguas de 1981, que propiciaba la formación de comunidades de aguas, que se limitan a administrar las obras de riego y que permitía gravar y vender los derechos de aprovechamiento. Este proyecto “...se encontró con la férrea oposición de los dirigentes indígenas. Según ellos, la aplicación del programa les impondría una forma de organización desconocida, que se apartaba por completo de sus costumbres y que, en definitiva, desarticularía sus organizaciones comunitarias tradicionales" (Cuadra 2000: 96-97). Los atacameños de los ayllus, al inscribir el total de los caudales de los ríos de modo comunitario, salvaguardaron las formas de usos y aprovechamiento tradicional, donde el agua y la tierra son indivisibles.

Resuelta la inscripción comunitaria de derechos de aguas, las asociaciones de regantes acuerdan que se efectúen los estudios para desarrollar el diseño y construcción de estanques acumuladores nocturnos de aguas en los ayllus

12 La regulación para el acceso y la gestión del agua en el país se rige por el Código de Aguas de 1981, dictado por el régimen militar de la época, mediante el cual se privatiza el agua y se otorgan sus derechos a perpetuidad, separando el agua del dominio de la tierra, para permitir su libre compra y venta. 
de Guachar y Solor, destinados a reducir el número de días entre turnos y aportar caudales suficientes a los ayllus más lejanos de la zona de captación en Cuchabrache, período que abarcó entre 1995 a 1999. Para dar inicio a la construcción, se firmó un acuerdo entre los regantes atacameños del río San Pedro, con el Instituto de Desarrollo Agropecuario (INDAP) y la Comisión Nacional de Riego (CNR). Este acuerdo consideró el financiamiento de los aproximadamente 600 millones de pesos (un millón de dólares) necesarios para la primera etapa. El 10\% del valor, 60 millones de pesos, fue de cargo de la Asociación de Regantes del Río San Pedro, monto prestado por INDAP con un interés penal de 9,8\%. La construcción de los estanques y la deuda atacameña vendrán a desarrollar un lamentable conflicto que acabó en el intento de confiscación de los derechos de aguas por parte del organismo fiscal. En efecto, los regantes atacameños pagaron dos cuotas, la primera en el año 2000 y la segunda en 2001 , pero la falta de fondos de la asociación de regantes les impidió enterar la tercera cuota, lo que creó un grave conflicto ya que el INDAP, en marzo de 2003, procedió a confiscar los derechos comunitarios de aguas, para liquidarlos y pagarse la deuda más los intereses. La expropiación de facto de las aguas de riego, un acto, además, carente de legalidad, dio origen a un movimiento en defensa del río, encabezado por la Asociación de Regantes del Río San Pedro y apoyado por la Asociación de Regantes del Río Vilama, las comunidades indígenas atacameñas y la sociedad civil de San Pedro de Atacama (Estrella del Loa 17/09/2003). La insólita medida de embargo de las aguas ancestrales, protegidas por los artícu$\operatorname{los} 13^{\circ}$ y $22^{\circ}$ de la Ley Indígena 19.253, fue una torpeza de los funcionarios que administran el modelo agrario neoliberal. Ante la imposibilidad de sostener la inaudita medida, la institución fiscal solicitó el embargo judicial de los bienes de la Asociación de Regantes del Río San Pedro, procediéndose a incautar un camión de la organización ${ }^{13}$. La confianza de los atacameños hacia el organismo público quedó deteriorada, pero la decepción fue mayor en 2005, cuando se inauguraron los estanques de acumulación nocturna. Los estanques Guachar, con una capacidad de $34.000 \mathrm{~m} 3$, y Solor, de $11.000 \mathrm{~m} 3$, buscaban reducir los turnos de 20 a 12 días y dar seguridad de riego a los ayllus más distantes de las bocatomas del río San Pedro. Sin embargo, al entrar en funcionamiento evidenciaron problemas de diseño, pues los estanques no lograban llenarse por las noches ni vaciarse por las horas del día (Reddersen 2005) ${ }^{14}$. A esto se sumó la reducción del caudal del río en la década de 2000 , con lo cual "se logró usar el estanque de Guachar (y el de Solor)...sólo el $50 \%$ de la capacidad de almacenaje, debido a la merma de agua que existe en el río San Pedro" (Reddersen 2005: 5). Estas nuevas obras, además, encarecieron los costos de riego, debido a la necesidad de una constante mantención para limpiar las toneladas de arena decantadas en los acumuladores nocturnos. Lo anterior no permitió dar cumplimiento al objetivo de reducir los turnos de riego, que continuaron en los 20 días promedio ${ }^{15}$. Los estanques solo sirvieron al objetivo de asegurar agua en tiempo y cantidad a los ayllus ubicados en el sector sur de San Pedro de Atacama, los que hasta antes de las obras habían sido los más perjudicados, principalmente debido a su lejanía de la cabecera del sistema de captación del agua para riego, puesto que en el largo recorrido ocurría mayor pérdida por infiltración, evaporación y robos de agua, y se alargaba el tiempo de recepción del turno, lo que se había agudizado con la disminución progresiva de los caudales.

\section{Reducción de las tierras regadas y de los cultivos}

Tras los distintos intentos de mejoramiento del sistema de riego, actualmente, los regantes en los ayllus de San

13 Causa rol 12.737, Juzgado de Policía local de Calama, mayo de 2003.

14 El diagnóstico del funcionamiento de los estanques es el siguiente: el estanque Guachar, de mayor capacidad: “... demora 17 horas en llenarse y 18 en vaciarse”; el segundo, problemas de cálculo y de construcción: "Su operación se ve dificultada por el hecho que su vertedero no tiene la capacidad de vaciar el caudal de exceso y sus válvulas de vaciado no botan el caudal suficiente para vaciar el estanque... (presenta) muchos problemas de rebalse de canales por la poca capacidad de éstos y por el mal estado de su construcción" (Reddersen 2005: 5).

15 Entre los grupos de regantes, las normativas internas también incluyen tener su propia manera de distribuir el caudal de riego, correspondiente a sus grupos respectivos; por ejemplo, en el grupo $\mathrm{N}^{\circ} 7$ la cantidad de agua se calcula por el número de vueltas del marco partidor: en el marco partidor hacia el canal derivado Estanque son tres vueltas, y dos vueltas en la compuerta que sale del estanque acumulador, desde donde se reparte el agua hacia los regantes de este grupo. Otros grupos se guían por una línea trazada en el canal en el sector de reparto, que indica la altura de la lámina de agua, correspondiente al caudal asignado a ese grupo y sector de riego. 
Pedro de Atacama mantienen los turnos de riego cada 18 a 22 días, ostentando cada regante derechos de uso de aguas proporcionales al tamaño de la tierra que posee. En la Asociación del Río San Pedro se considera, por cada hectárea de propiedad, la entrega de dos horas de riego para cultivos de trigo, alfalfa y frutales, y en el caso de cultivos de maíz y hortalizas, se otorga medio turno más, es decir, una hora más por hectárea, regándose los terrenos por inundación para ayudar al lavado de sales del suelo $^{16}$. Se sigue operando con grupos de riego - siete en el río San Pedro y uno en el Vilama- y se mantiene la misma distribución de aguas que se estableció en el año 1964, aunque mejorada con las obras de infraestructura realizadas en los últimas dos décadas, que han amorti-

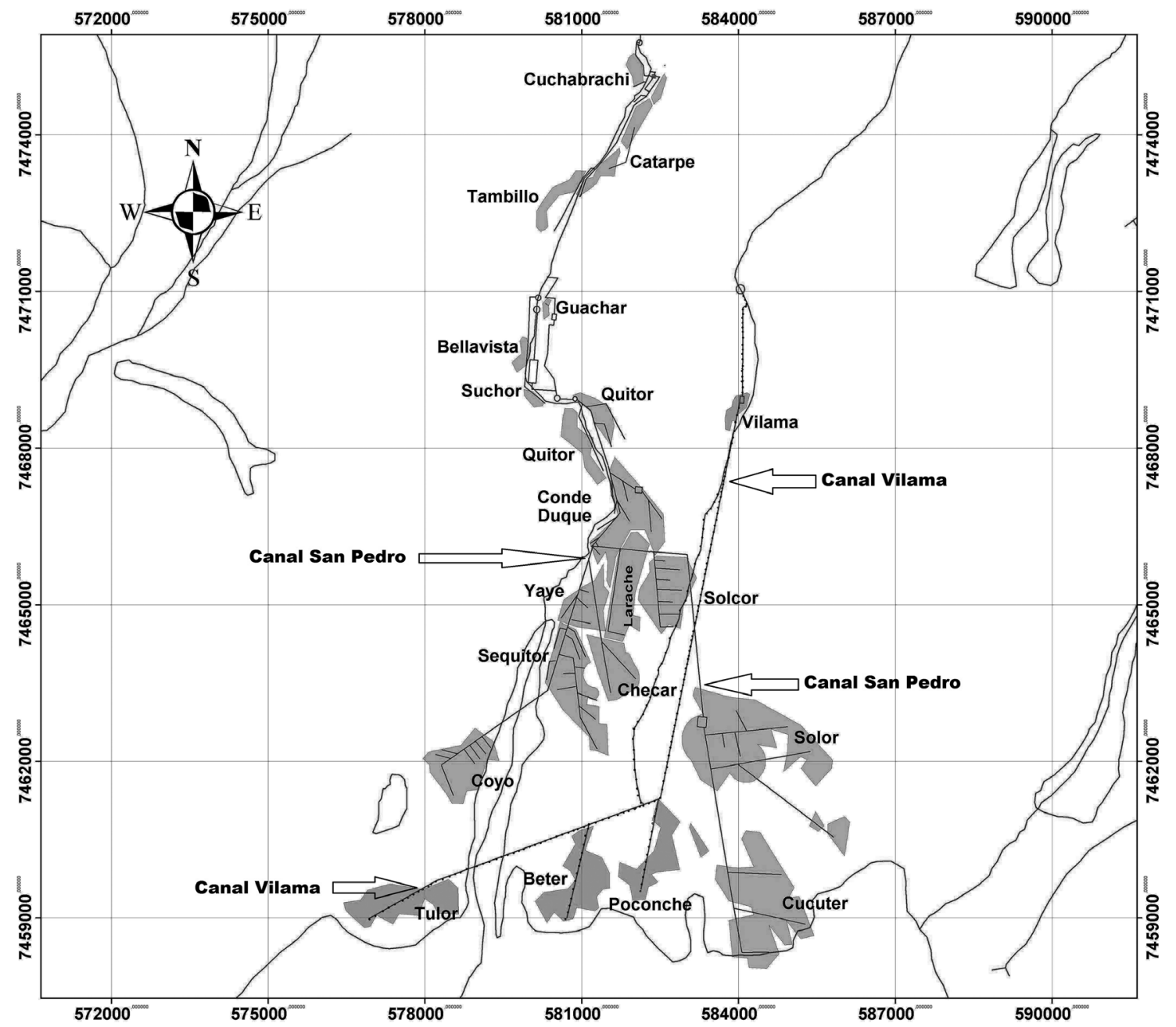

Figura 3. Croquis Ayllus y canales de riego.

Fuente: cartografía confeccionada por Héctor Aedo. Ver Aedo (2011)

16 El riego por inundación permite el lavado de sales de los suelos y mantiene largo tiempo la humedad del mismo hasta antes del punto de marchitez permanente del cultivo. Esta técnica de riego es adecuada a la textura de los suelos franco arenosos, de buen drenaje, que permiten mejor retención de humedad, a excepción del ayllu de Vilama y los del sector sur, Tulor y Beter, que al ser arenosos tienen un drenaje excesivo. guado en parte los impactos que ha generado la disminución de los caudales de los ríos en los últimos cincuenta años, de 1964 a 2014 (ver Tabla 1).

El proceso de parcelación de los terrenos se ha agudizado con la demanda de tierra desde el sector turismo. Esto 


\begin{tabular}{|c|c|c|c|}
\hline Tamaño de los predios & \multicolumn{2}{|c|}{$\mathbf{N}^{\mathbf{0}}$ de Predios en años comparativos } & \multirow{2}{*}{ Variación de superficie (hectáreas) } \\
\hline & 1964 & 2014 & +112 \\
\hline$-0,5$ ha & 361 & 473 & +40 \\
De 0,5 a 1 ha & 251 & 291 & +50 \\
De 1 a 5 ha & 376 & 426 & -16 \\
De 5 a 10 ha & 35 & 19 & -3 \\
Más de 10 ha & 12 & $\mathbf{1 2 1 8}$ & $+\mathbf{1 8 3}$ \\
\hline Total & $\mathbf{1 0 3 5}$ & \\
\hline
\end{tabular}

Tabla 2. Superficies prediales en los ayllus de San Pedro de Atacama (1964-2014).

Fuente: Aranda et al. 1964, Arrau Ing. 2014.

ha significado el aumento de la complejización del sistema de riego. El regante, desde que recibe el agua, debe operar el llenado de cada melga o era, más pequeños y que exige mayor eficiencia, lo que incluye calcular en el momento cuánto caudal ir asignando a cada melga puesto que, aunque existe un caudal por grupo y por regante, este varía generalmente hacia una menor disponibilidad. Al mismo tiempo que se riega, se deben ir repasando los pretiles para evitar desmoronamientos. Así, el regante debe ocupar mayor tiempo y ser muy preciso, para que no se desbarate el verdadero puzzle que es regar en esas condiciones. La complejidad de la parcelación de tierra se refleja también a escala del grupo y del sistema global de riego, ya que con el aumento del número de regantes, aumenta la demanda por el agua y los conflictos.

Las aguas siguen siendo comunitarias, y se aplica el derecho consuetudinario basado en normas colectivas y sanciones a los regantes que las trasgreden. Algunos ejemplos ilustran esta situación. En el ayllu Conde Duque, la sanción a la violación de la norma de riego - turno y uso del agua - varía en virtud de la gravedad del hecho, y es cotejada con los atenuantes que presente el responsable, pudiendo condenársele a: a) pagar una multa en dinero que no supere la establecida en los estatutos; b) enviar un doble peón o trabajador a trabajo el año siguiente; c) pagar al peón contratado por el grupo de riego, para que realice la labor no asumida por el infractor; $y \mathrm{~d}$ ) asignarle la limpieza de un tramo de canal, la más dificultosa, o de un sifón, para que la ejecute en un tiempo determinado. Si el regante socio no cumple la sanción impuesta por la asamblea, se expone al corte del agua de riego hasta que cumpla la obligación. Si su comportamiento se repite, se le margina de futuros beneficios relacionados con el riego y proyectos productivos. Si el regante del grupo no cumple y cae en rebeldía, es denunciado a la Junta Central de Regadío del Río San Pedro para que sea sancionado de acuerdo a los Estatutos. El derecho consuetudinario atacameño actúa desde "abajo hacia arriba", desde las bases a la directiva, prevaleciendo el derecho comunitario en la estructura de la organización. El acceso a las aguas de riego se perpetúa en el derecho de cada propietario u ocupante de tierra, incluyendo los no atacameños que han adquirido terrenos agrícolas en los ayllus. Esta política de inclusión y de vínculo indisoluble entre agua y tierra, y tiene como condición que los propietarios sigan cultivando sus terrenos y que se rijan por los estatutos y acuerdos de las asambleas (ver Tabla 2).

Pese a la constitución de los derechos consuetudinarios en los ayllus de San Pedro de Atacama, la disminución de la superficie regada y cultivada se ha reducido. Entre 1964 y 2014, el descenso de los caudales medios de los ríos San Pedro y Vilama ha sido uno de los factores de reducción de las tierras cultivadas (ver Tabla 1). En efecto, al comparar los estudios de Aranda et al. (1964) y Arrau Ing. (2014), las tierras potencialmente susceptibles de ser regadas han descendido de 1754 a 1474 hectáreas. Por su parte, las tierras efectivamente regadas o cultivadas han bajado de 1210 hectáreas en 1964, a 709 en 2014. Esto significa que la superficie potencialmente cultivable se redujo en 280 hectáreas (16\%) y la superficie efectivamente cultivada disminuyó en 501 hectáreas (41\%), mientras que en el mismo período se reduce el agua disponible para riego en cerca del 50\% (Arrau Ing. 2014), como se expresa en la tabla 3 .

En el caso de los cultivos, la matriz tradicional y dominante en los ayllus de San Pedro de Atacama ha sido, desde la década de 1960, la formada por el trigo, el maíz y la alfalfa. Estos cultivos han representado siempre una gran proporción de la superficie cultivada: 93\% en 1964, 98\% en $1995,92 \%$ en 2000 y $91 \%$ en 2014 . La superficie cultivada y regada bajó en un 42\% en el período 1964 a 


\begin{tabular}{|c|c|c|c|}
\hline Año & $\begin{array}{c}\text { Sup. Potencial } \\
\text { de riego (ha) }\end{array}$ & Sup. regada y cultivada (ha) & \% reducción sup. regada \\
\hline 1964 & 1.754 & 1.210 & $31 \%$ \\
\hline 2014 & 1.474 & -509 & $48 \%$ \\
\hline Disminución (ha) & -280 & $41 \%$ & \\
\hline \% reducción & $16 \%$ & & \\
\hline
\end{tabular}

Tabla 3. Disminución de tierras regadas en los ayllus de San Pedro de Atacama (1964 y 2014).

Fuente: comparación en base a datos proporcionados por Aranda (1968) y Arrau Ing. (2014).

\begin{tabular}{|l|c|c|c|c|}
\hline Cultivos & 1964 & 1995 & 2000 & 2014 \\
\hline Alfalfa & 801 & 795 & 794,3 & 495,2 \\
\hline Alfalfa + Maíz & $\circ$ & 0 & 4,9 & 0 \\
\hline Otras praderas & $\circ$ & $\circ$ & 0,7 & 14,1 \\
\hline Trigo & 176 & 6,5 & 14,0 & 0 \\
\hline Maíz & 147,2 & 53,7 & 48,8 & 134,5 \\
\hline Frutales & 32 & 11,7 & 11,2 & 49,3 \\
\hline Hortalizas & 0 & 2 & 13,2 & 8,1 \\
\hline Otros & 53 & 1,4 & 1,4 & 7,8 \\
\hline Total Ha & 1209,2 & 870,3 & 888,5 & 709 \\
\hline
\end{tabular}

Tabla 4. Distribución de cultivos en San Pedro de Atacama: 1964 a 2014 .

Fuente: Aranda et al. 1964; R\&Q 1995; Sepúlveda 2000; Arrau Ing. 2014.

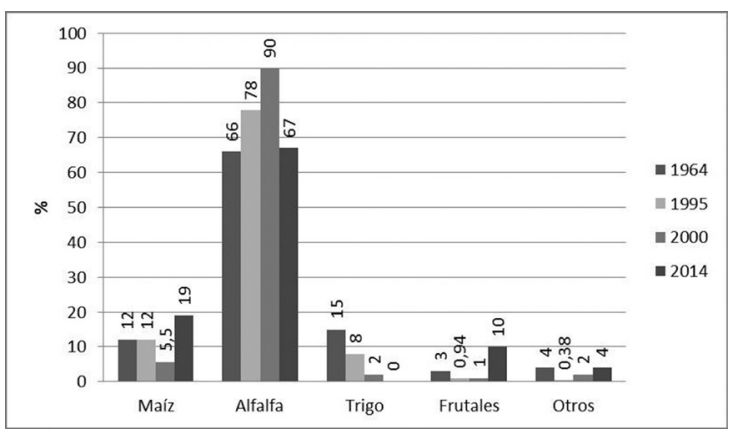

Figura 4. Distribución porcentual de cultivos en la localidad de San Pedro de Atacama y sus ayllus entre 1960 y 2014.

Fuente: elaboración propia en base a Aranda 1964, R\&Q 1995 , Gundermann y González 1995, Sepúlveda 2000 y Arrau Ing. 2014.

2014, pero la tendencia general de los cultivos tradicionales en los últimos cincuenta años ha sido la siguiente: La alfalfa, proporcionalmente, es el cultivo que mantiene la participación más alta, el maíz repunta en superficie en la última década, y el trigo desaparece como cultivo. Así también los frutales y las hortalizas, aunque representan baja proporción, han incrementado su superficie cultivada en los últimos años. 
En el otro extremo se encuentra el trigo, el único cultivo tradicional que en la última década ha desaparecido. En efecto, en 2014 no se registra siembra (Arrau Ing. 2014) y ha quedado fuera de los cultivos de autoconsumo que se introdujeron en el período colonial. Es muy probable que, para el uso alimenticio y las fiestas de carnaval, los granos y la harina de trigo estén siendo comprados en el comercio para continuar con la elaboración de alimentos como el locro, el ulpo y el cocho, hacer la Ulpada y fabricar pan con figuritas que sirven para el pago a las tierras durante la siembra (Uribe et al. 2013) ${ }^{19}$.

Los frutales, como se aprecia en la tabla anterior, han incrementado su superficie y participación en la estructura de cultivos de los ayllus en la última década. Se han plantado árboles frutales entre las praderas, como estrategia para optimizar el agua y aprovechar los nutrientes que aporta la alfalfa. Los árboles más antiguos se mantienen sin manejo y con problemas de plagas y enfermedades, a pesar de que muchos atacameños conocen de las podas e injertos de plantas. Otros cultivos que han aparecido desde 1995 son las hortalizas, cultivos que han estado relacionados con el Programa de Transferencia Tecnológica de INDAP, y el Programa Chile Norte ${ }^{20}$. Con ellos, se desarrolló el cultivo de hortalizas y flores con riego por goteo. La transferencia tecnológica hacia estos cultivos continuó con los programas de mejoramiento de suelos, asistencia técnica y unidades de demostración para mejoramiento de praderas, incorporación de hortalizas y frutales, promovidas por el Servicio Agrícola y Ganadero SAG, INDAP, la CNR y la Universidad Arturo Prat ${ }^{21}$. Estos programas, con fuerte enfoque desarrollista, priorizaron la innovación y producción con fines de comercialización, de tal manera que se dio énfasis a los aspectos técnicos y no consideraron la relevancia de los aspectos socioproductivos particulares de estos sistemas. Los nuevos cultivos han tenido la franquicia de contar con medio turno más para su riego, pero aun las superficies cultivadas son pequeñas, pues las hortalizas no sobrepasan las nueve hectáreas a 2014 y los frutales, que han incrementado su área de plantación, cubren 49,3 hectáreas.

Finalmente, en cuanto al maíz, es el cultivo tradicional que aparece con cambios positivos en la superficie sembrada. Actualmente ha recuperado las superficies que tenía en 1964, aumentando su participación en la estruc- tura de cultivos al 19\% en 2014, esto es producto de la baja general de los terrenos sembrados. Este cultivo es el más demandante de agua pues, junto a las hortalizas y frutales, se le otorga medio turno más de riego, es decir, los cultivadores tienen derecho a tres horas de riego por hectárea. La siembra del maíz se realiza tres o cuatro días después de efectuarse el riego, y la semilla se prepara remojándola un día antes de la siembra. Se utiliza un mínimo de labranza, y en algunos casos el maíz se combina con siembra de zapallos y chacras para protegerlo de las heladas. También se siembra combinado con alfalfa, para aprovechar la liberación de nitrógeno de la especie forrajera ${ }^{22}$.

La mantención del maíz en la matriz atacameña puede estar asociada a que es un cultivo adaptado al suelo salino y a las condiciones químicas de las aguas, pero también

19 El locro es un guiso a base de trigo seco pelado con verduras y carne o charqui. El ulpo es harina tostada que se usa con agua como bebida. El cocho es un alimento espeso a base de agua caliente y harina tostada. La harina de trigo se utiliza en distintos ritos en que se mezcla con aloja, lo que llaman Ulpada (Uribe et al. 2013).

20 El Programa Chile Norte fue un programa de cooperación entre el gobierno de Chile y la Unión Europea para el desarrollo de proyectos de riego y productivos agrícolas en áreas rurales.

21 Entre los años 1998 y 2001 , la Universidad Arturo Prat y la Comisión Nacional de Riego (CNR) desarrollaron un programa de asistencia técnica e investigación para el desarrollo de cultivos, en el cual se logró demostrar que, con incorporación de nueva tecnología y mejoramiento de los manejos técnicos, se puede mejorar la productividad de los cultivos tradicionales y la incorporación de nuevos cultivos (ver Universidad Arturo Prat et al. 2000).

22 Sobre el cultivo del maíz en terrenos de menos de un cuarto de hectárea, en las siembras se ocupan de una a dos personas y se utiliza solo azadón y pala, trazando los surcos (no más altos que el alto del azadón, unos $30 \mathrm{~cm}$ ). Luego se "raya", o sea, se hacen las hileras de $80 \times 30 \mathrm{~cm}$, con una profundidad de $10 \mathrm{~cm}$, donde se depositan cerca de tres semillas, a la vez que se van arreglando los bordos de las melgas. Para superficies se utiliza la tracción animal, motocultores e incluso tractores, aunque esta maquinaria aún no es de uso masificado y puede ser perjudicial en terrenos pequeños. Respecto a las cualidades de la alfalfa, existe un conocimiento empírico de los atacameños: "la alfalfa uno la combina con otros cultivos o la deja para arreglar los terrenos, porque la alfalfa arregla la tierra" (Apolinario Coca 2010). También las tunas con sus paletas, al igual que el cachiyuyo (átriplex atacamensis) y chañares, se utilizan como cerco vivo para proteger los cultivos de heladas, del viento y de los animales. 
a que es un cultivo que se encuentra muy vinculado a las prácticas culturales y cuyo origen es prehispánico. Muy probablemente es el cultivo que nunca se ha dejado de sembrar. Actualmente sigue siendo un cultivo relevante, pese incluso a que el costo de producirlo resulte más caro que comprar un maíz traído desde fuera. En los ayllus de San Pedro de Atacama se conocen cuatro variedades: capia (maíz de grano blanco), morocho (maíz de grano amarillo), pisangalla (maíz de grano amarillo y pequeño) y negro (maíz de grano de pigmentación oscura). Su importancia cultural también es clave para comprender la permanencia del cultivo, pues es usado como alimento humano y para el ganado, tiene uso medicinal y se ocupa en fiestas y rituales. Con los granos de los maíces se hacen alimentos como la patasca, el sango, el "pan de sangre", las capias y las roscas de harina negra. Las hojas o chalas y la materia verde del maíz se ocupan como alimento del ganado, y el hongo del maíz (Ustilago maydis) se usa como medicina. Finalmente, los subproductos del maíz se usan en ritos y festividades para los días de los muertos y en el carnaval de los ayllus de San Pedro. Para la mesa de Todos los Santos se ocupan las flores de maíz como ornamentación, y con su harina se hacen las capias como ofrendas a los muertos. En período de carnaval se usa la planta como adorno y estandarte en las celebraciones y bailes (Grebe e Hidalgo 1988; Escalante 2001; Uribe et al. 2013).

Es posible que el maíz, junto a los demás cultivos, sean la razón más poderosa para mantener vigente la demanda de mejoramiento de las condiciones de riego, como la construcción de un embalse de regulación de aguas y el mejoramiento de los canales e infraestructura general de distribución y regulación de las aguas. Estos aportarían a dar forma a una nueva fase de los cambios y permanencias en la relación entre agua, riego y cultivos en los ayllus de San Pedro de Atacama.

23 La patasca es un guiso que se elabora dejando el maíz secar, se pela con ceniza y se prepara con verduras y carne. El sango es otro guiso, a base de harina de maíz con chicharrón, ajo, cebolla y ají. El "pan de sangre" se prepara con harina de maíz mezclada con sangre y chicharrón, luego se fríe. Las capias son un tipo de galleta con fines rituales.

\section{Reflexiones finales}

Los cultivos y las labores agrícolas permiten apreciar que, a pesar de su franca disminución entre los años 1964 y 2014 a casi la mitad de la superficie cultivada, esta es la única actividad que articula ancestralmente el sistema de administración del agua de los ríos San Pedro y Vilama, con el uso de los cauces hídricos en el riego predial. El riego es así una de las actividades de mayor relevancia en la organización consuetudinaria atacameña, y forma parte principal de la vida social y productiva en los ayllus de San Pedro de Atacama. A su vez, la actividad agrícola, la reproducción anual de las siembras y los calendarios de cosechas hacen conciencia entre los atacameños acerca de la importancia del agua, y les advierten sobre la reducción constante de los caudales de los ríos. Además, la actividad agrícola es la reproductora del paisaje tradicional de los ayllus, que se construye a partir de las tareas y labores de los diversos cultivos y del manejo del agua y del riego que se reproduce, en promedio, cada veinte días.

Pareciera que entre los años estudiados, 1964 a 2014, en los ayllus de San Pedro de Atacama ha existido un "descenso en equilibrio" de los factores agua y cultivos, pues es notorio que a medida que disminuyen a la mitad los caudales medios disponibles, a la vez se aprecia una baja de la superficie cultivada, aunque en menor proporción, ralentización que podría ser atribuible a los constantes esfuerzos a lo largo de estas cinco décadas por incrementar la eficiencia del riego. Las mejoras de la eficiencia en el riego continúan siendo la principal preocupación y demanda atacameña, puesto que de ello dependen la permanencia de sus medios de vida tradicionales y la reproducción de sus valores culturales.

Es necesario destacar que el modelo atacameño considera indisoluble la unidad entre agua y tierra. Esta unidad ha sido fundamental para dar continuidad al aprovechamiento comunitario de las aguas y afianzar la cohesión cultural productiva y organizacional en torno al riego en los ayllus. Por otra parte, si bien las organizaciones de riego del río San Pedro y del río Vilama lograron rechazar el modelo neoliberal aplicado a los derechos de aguas, esto no se ha logrado con la política agraria de igual signo, que sigue considerando a los atacameños y demás pequeños propietarios como inviables económicamente, objetos de subsidios y excluidos del modelo agroexpor- 
tador y de articulación con la agroindustria. De allí que la política de desarrollo agrario hacia los atacameños se caracterice por no promover resueltamente los cultivos tradicionales como la alfalfa, el maíz y el trigo, y se promuevan preferentemente "cultivos comerciales" como flores, hortalizas y algunos frutales. Esta política no considera que los cultivos tradicionales, además de su rol productivo y de autoconsumo, son a la vez parte de un sistema silvoagropecuario que genera relaciones de reproducción cultural. Además, a los cultivos comerciales se les adosa un paquete de agroquímicos: fertilizantes, pesticidas, fungicidas y herbicidas, que juntos rompen la producción orgánica tradicional, introducen riesgos ambientales, encarecen la producción y generan dependencia hacia estos productos. Igualmente, se han introducido invernaderos que han fracasado por no exigir mano de obra intensiva, que en las economías atacameñas se destinan a una multiplicidad de actividades, cultivos, ganado, participación en organizaciones comunitarias, elaboración de subproductos silvoagropecuarios e inclusive los trabajos asalariados extraprediales. Estas medidas modernizantes pretenden generar unidades empresariales en los predios atacameños, pero ellas contravienen la cultura agraria en los ayllus, por lo cual generan escasos resultados. Aunque la respuesta atacameña no ha sido cerrada a los cambios tecnológi$\cos$ e innovaciones productivas agrarias, estos se han mantenido bajo un proceso de adaptación cultural a los tiempos, mano de obra y de conciliación con los conocimientos tradicionales. En efecto, los propios agricultores atacameños han aprovechado la inversión pública, ideando estrategias de adaptación para dar respuesta a sus propias necesidades. Es así como algunos complementan los nuevos conocimientos y tecnologías con las prácticas ancestrales, por ejemplo, combinando el riego por goteo con el riego por inundación, para así mantener el lavado de sales de los suelos, o cuando en sus estrategias productivas combinan los cultivos tradicionales con la producción de hortalizas para autoconsumo y venta, destinadas al mercado del turismo. También los agricultores atacameños han aprovechado los programas de recuperación de suelos para renovar las praderas de alfalfa y aumentar la superficie de maíz (ver tabla 4). Igualmente, han hecho uso de la asistencia técnica para mejorar las condiciones sanitarias del ganado, todo lo cual tiene por objeto mantener el sistema tradicional mediante el mejoramiento de las condiciones productivas actuales.
Este último punto es clave para comprender que, si bien en la actualidad la superficie cultivada en los ayllus se ha reducido casi a la mitad de lo existente en 1964, los atacameños han ideado una estrategia de cultivos para aprovechar las aguas de riego, que también han disminuido. Esta consiste en la mantención de la alfalfa, que cubre aproximadamente el $70 \%$ de la superficie cultivada. Este cultivo soporta hasta cuarenta días entre riego, demanda pocos cuidados y horas de mano de obra, y se mantiene productivo en el tiempo. La alfalfa se complementa con el maíz, que cubre un $20 \%$ de la superficie, y con frutales y hortalizas que completan la superficie cultivada. Esta estrategia atacameña de producción agrícola en condiciones de reducción de aguas y tierras cultivadas estaría asociada a formas complementarias de ingresos, procedentes de otras actividades como el trabajo asalariado, la inserción en el turismo, los servicios y el comercio. En este cuadro, la agricultura juega un papel de retaguardia, manteniéndose a nivel mínimo de reproducción y autoconsumo.

\section{$\leftrightarrow$ Conclusiones}

A pesar de la aparente estabilidad y equilibrio precario entre agua, riego y cultivos, es posible advertir lo que podría ocurrir en un futuro cercano con la agricultura de los ayllus de San Pedro de Atacama. Sabemos que los ayllus, localizándose en un hábitat de desierto, dependen inevitablemente de las variables medioambientales, especialmente de las precipitaciones que se producen en la puna y cordillera, donde se forman los ríos San Pedro y Vilama, que aportan sus caudales al riego de los ayllus. En este trabajo construimos una completa serie de caudales para los ríos San Pedro y Vilama entre los años 1940 a 2014, luego analizamos los cambios en la infraestructura de riego y sus etapas de transformación, y enseguida elaboramos cuadros comparativos de tierras y cultivos para los años 1964, 1995, 2000 y 2014. El conjunto de esta información constata la reducción de las superficies potenciales agrícolas, la reducción de las superficies cultivadas y la variación en la participación de los cultivos. En cifras implican lo siguiente:

a) Que la disminución de los caudales medios anuales de los ríos San Pedro y Vilama ha sido drástica. En el caso del río San Pedro, de un caudal medio de 1127 l/s en la década de 1940, bajó a un promedio de $620 \mathrm{l} / \mathrm{s}$ en los pri- 
meros 15 años del siglo XXI (2000 a 2014), lo que representa una disminución del $45 \%$ de caudal. En el caso del río Vilama la situación es aún más dramática, pues en la década de 1940 el caudal medio anual era de $332 \mathrm{l} / \mathrm{s}$, pero descendió a 134,5 l/s en la década del 2000, para nuevamente descender a $76,7 \mathrm{l} / \mathrm{s}$ entre los años 2011 a 2014, lo que equivale a una reducción del $77 \%$ del caudal medio. Esta importante disminución, de prolongarse o profundizarse, en el corto plazo estaría poniendo en franco peligro el abastecimiento de aguas de riego a los ayllus de Vilama, Poconche, Beter y Tulor. Lo mismo ocurriría si el río San Pedro continúa con la tendencia de disminución de sus caudales, lo que agudizaría el estrés hídrico en los ayllus que riega.

b) En los últimos cincuenta años, las superficies agrícolas potenciales han disminuido en 280 hectáreas. En efecto, en 1964 se consideraban 1754 hectáreas, mientras en 2014 se contabilizaban 1457 hectáreas. Lo mismo ocurre con la superficie regada y cultivada, donde la reducción en los últimos cincuenta años ha sido de 501 hectáreas. Esto significa que en 1964 se contabilizan 1210 hectáreas cultivadas, pero en 2014 estas habían descendido a 709 hectáreas, lo que significa una reducción del 41,4\%.

c) De los cultivos tradicionales, solo ha desaparecido el trigo. El maíz, aparte del autoconsumo, está asociado a los ritos a la tierra, la fertilidad y a las celebraciones que recuerdan a los antepasados, y posiblemente sea por esto que ha prevalecido sobre el trigo. Mientras, la alfalfa sigue ocupando la mayor superficie cultivada, dada su importancia en la mantención del ganado, base importante en la dieta familiar y como suerte de reservorio de seguridad en caso de emergencia, pero que también tiene una significación identitaria en estos sistemas agrícolas andinos.

d) La permanencia de los cultivos tradicionales, pese a la crisis hídrica y contrario a las políticas del Estado de innovación para la comercialización, demuestra que siguen siendo importantes más allá de una valoración económica. La producción de estos cultivos, y con ello el riego, sigue siendo la base material en que se reproduce esta cultura y se mantienen los lazos familiares y sociales de su identidad. De esta permanencia depende también la sostenibilidad del material biológico en el frágil entramado ecológico de estos sistemas.

Frente a esta baja de los caudales y tierras cultivadas, se han venido implementando mejoramientos en la infraestructura de riego que aseguran la eficiencia y la mejor distribución de las aguas. Pero se debe tener presente que, si en la actualidad se mantienen los turnos en 20 días en promedio, es porque se está regando la mitad de las superficies de tierras existentes hace cincuenta años. ¿Qué ocurriría con los turnos si las tierras se pusieran en producción en su totalidad?, ¿es el agua disponible una limitante para expandir la economía agraria en los ayllus de Atacama? Si en las actuales condiciones la superficie cultivada tuviese una tendencia a incrementarse, y los caudales medios anuales de los ríos San Pedro y Vilama siguiesen descendiendo, ¿cómo se afectaría el equilibrio actual entre agua, riego y superficie cultivada?, icómo se afectaría el tejido del sistema social, económico/productivo y ambiental frente a la crisis del agua? Es claro que esta discusión seguirá pasando por la gestión, infraestructura y regulación de las aguas, y por nuevos mejoramientos en los sistemas de riego, como ha ocurrido en los últimos cincuenta años. Sin embargo, la importancia del agua en San Pedro de Atacama evidencia la necesidad de asumir, con urgencia, una responsabilidad colectiva en pos de salvaguardar este recurso vital, que parte de los propios regantes pero es extensiva a cada uno de los actores que intervienen en este territorio.

Agradecimientos Agradecemos a Víctor Aedo por el aporte de mapas y al Servicio Agrícola y Ganadero por el aporte de información estadística relevante, especialmente a Diego Ferrer. También agradecemos a los evaluadores, por sus sugerencias para mejorar el manuscrito. 


\section{* Referencias citadas}

AEDO, H. 2011. Conflictos por el agua en los ayllus de San Pedro de Atacama, II Región. Memoria de Geografía. Facultad de Arquitectura y Urbanismo, Universidad de Chile, Santiago de Chile.

ALONSO, H. 1997. Geoquímica de aguas en el altiplano. Una aproximación. En El Altiplano: Ciencia y Conciencia de los Andes: actas del II Simposio Internacional de Estudios Altiplánicos, 19 al 21 de Octubre de 1993, Arica, Chile, R. Charrier (Ed.). Universidad de Chile, Santiago de Chile.

ALTIERI, M. A. 1985. Developing pest management strategies for small farmers based on traditional knowledge. Bulletin of the Institute for Developmental Anthropology 3: 13-18.

1996. Enfoque agroecológico para el desarrollo de sistemas de producción sostenibles en los Andes. Centro de Investigación, Educación y Desarrollo, Lima.

ALTIERI, M. A. y C. I. NICHOLLS. 2000. Agroecología: teoría y práctica para una agricultura sustentable. Programa de las Naciones Unidas para el Medio Ambiente, Red de Formación Ambiental para América Latina y el Caribe, México, D.F.

ARANDA, X. 1964. San Pedro de Atacama. Elementos diagnósticos para un plan de desarrollo local. Informaciones Geográficas XI-XIV, especial: 19-61.

ARANDA, X., R. BARAHONA y R. SAA. 1968. Elementos diagnósticospara un plan de desarrollo local en San Pedro de Atacama. CORFOUniversidad de Chile, Santiago de Chile.

ARRAU INGENIERÍA E.I.R.L. 2014. Estudio de PrefactibilidadMejoramiento Sistema de Riego en Río San Pedro. San Pedro de Atacama.

BARROS, A. 2008. Identidades y propiedades: Transiciones Territoriales en el Siglo XIX Atacameños. Estudios Atacameños 35(2): $119-139$.

2009. Huyendo hacia adelante, mirando para atrás. Ponencia presentada en $53^{\circ}$ Congreso Internacional de Americanistas, México.

BARTHEL, T. 1986 [1957]. El agua y el festival de primavera entre los atacameños. Allpanchis XVIII(28): 147-184.

BEBBINGTON, A. 2007. Minería, movimientos sociales y respuestas campesinas: una ecología política de transformaciones territoriales. Instituto de Estudios peruanos, Lima.

BOELENS, R. A., D. ROTH y M. Z. ZWARTEVEEN. 2004. Pluralismo legal, derechos locales y gestión del agua: entre el reconocimiento analítico y la estrategia política. En Los pueblos indígenas y el agua: desafios del siglo XXI, pp. 161-197. El Colegio de San Luis, A.C., San Luis Potosí.

BOLADOS, P. 2014. Los conflictos etnoambientales de "Pampa Colorada" y "El Tatio" en el Salar de Atacama, Norte de Chile: Procesos étnicos en un contexto minero y turístico transnacional. Estudios Atacameños 48: 228-248.

BOMAN, E. 1991 [1908]. Antigüedades de la región andina de la República Argentina y del desierto de Atacama. Universidad Nacional de Jujuy, San Salvador de Jujuy.

BOWMAN, I. 1942 [1924]. Los senderos del Desierto de Atacama. Sociedad Chilena de Historia y Geografía, Santiago de Chile.

CADE-IDEPE CONSULTORES EN INGENIERIA. 2004. Diagnostico y clasificacion de los Cursos y cuerpos de agua Segun objetivos de Calidad, Cuenca Salar de Atacama. Centro de Información de Recursos Hídricos, Dirección Nacional de Aguas, Santiago de Chile.

CAJIAS, F. 1975. La Provincia de Atacama (1825-1842). Instituto Boliviano de Cultura, Editora Universo, La Paz.

CASTRO, V. 2001. Atacama en el Tiempo, Territorios, Identidades, Lenguas (Provincia El Loa, II Región). Anales de la Universidad de Chile VI Serie 13: 27-70.

CEPAL. 1991. América Latina y El Caribe: El manejo de la escasez de agua. Naciones Unidas, CEPAL, Santiago de Chile.

CONSORCIO GEOFUN-PROCIVIL. 2000. Diagnóstico y Propuesta de Fomento a la Agricultura Regada en la II Región. Comisión Nacional de Riego (CNR) II Región, Calama.

CUADRA, M. 2000. Teoría y práctica de los derechos ancestrales de agua de las comunidades atacameñas. Estudios Atacameños 19: 93-112.

DALANCE, J. M. 1975 [1851]. Bosquejo Estadístico de Bolivia. Universidad Boliviana, La Paz.

DELGADO, B. 1992. La agroecología en las estrategias del desarrollo rural: (una experiencia institucional). Centro de Estudios Regionales Andinos "Bartolomé de las Casas", Cusco.

DENIS, P. 1987 [1920]. La valoración del país. La Republica Argentina. Ediciones Solar, Buenos Aires.

DIRECCIÓN GENERAL DE AGUAS (DGA), MINISTERIO DE OBRAS PÚBLICAS (MOP). S. f. Información Oficial Hidrome- 
teorológica y de Calidad de Aguas en Línea http://snia.dga.cl/ BNAConsultas/reportes

ESCALANTE, M. 2001. La mesa de todos santos en San Pedro de Atacama, Chile. Chungara, Revista de antropología chilena 33(2): 245-248.

FONSECA, C. y E. MAYER. 1988. Comunidad y producción en la agricultura andina. Fomciencias, Lima.

FUENZALIDA, H. y J. RUTLAND. 1996. Estudio sobre el origen del vapor de agua que precipita en el invierno altiplánico. Informe Final. Universidad de Chile, Santiago de Chile.

GENTES, I. 2005. ¿Pagos sin derechos a los territorios y sus bienes? Una aproximación crítica a las políticas de servicios ambientales y valorización de recursos hídricos en las cuencas andinas. Cepal.org. http://www.cepal.org/drni/proyectos/walir/doc/walir53.pdf

GREBE, M. E. y B. HIDALGO. 1988 Simbolismo atacameño: un aporte etnológico a la comprensión cultural. Revista Chilena de Antropología 7: 75-97.

GUNDERMANN, H. 2002. Los Atacameños del Siglo XIX; Un Antropología Histórica Regional. Comisión Verdad Histórica y Nuevo Trato. Subgrupo de Trabajo Pueblo Atacameño. Ms.

GUNDERMANN, H. y H. GONZALEZ. 1995. Tierra, agua y sociedad atacameña, un escenario cambiante. En Agua, ocupación del espacio y economía campesina en la región atacameña, aspectos dinámicos. P. Pourrut y L. Núñez (Eds.), pp. 78-106. Universidad Católica del Norte, Antofagasta.

HIDALGO, J. 1984. Complementariedad ecológica y tributo en Atacama: 1683-1792. Estudios Atacameños 7: 422-442.

INDAP. 1992. Plan Operativo Agrícola II Región.

INE. 2007. Censo Agropecuario 2007. http://www.ine.cl/canales/ chile_estadistico/censos_agropecuarios/censo__agropecuario__o7_comunas.php

KALIN, M., F. SQUEO, H. VEIT, L. CAVIEDES, P. LEON y E. BELMONTE. 1997. Flora and Vegetation of Northen Chilean Andes. En El Altiplano: Ciencia y Conciencia de los Andes: actas del II Simposio Internacional de Estudios Altiplánicos, 19 al 21 de Octubre de 1993, Arica, Chile, R. Charrier (Ed.). Universidad de Chile, Santiago de Chile.

KLARE, M. 2003. Guerras por los recursos. El futuro escenario del conflicto global. Urano, Barcelona.
LEHNERT, R. 1995. Agua y religiosidad en el sector atacameño. América Indígena 55(3): 161-178.

LUCIC, M. C. 1997. Agua, derechos y cultura en los Andes del norte de Chile. Un enfoque desde la antropología jurídica. Chungara: Revista de antropología chilena 29(1): 63-80.

MARTÍNEZ, J. L. 1998. Pueblos del Chañar y El Algarrobo: Los Atacamas en el Siglo XVII. Ediciones de la Dirección de Bibliotecas, Archivos y Museos. Santiago de Chile.

MITCHELL, W. 1981. La agricultura de riego en la sierra central de los Andes: implicaciones para el desarrollo del Estado. En $\mathrm{La}$ tecnología en el mundo andino: Runakunap Kawsayninkupaq Rurasqankunaqa, H. Lechtman y A. M. Soldi (Comps.), pp. 135-167. Universidad Nacional Autónoma de México, México, D. F.

MONSTNY, G., F. JELDES, R. GONZALEZ y F. OBERHUASER. 1954. Peine un Pueblo Atacameño. Instituto de Geografía. Facultad de Filosofía, Universidad de Chile, Santiago de Chile.

MUNIZAGA, C. 1958. Relatos Populares de Socaire. En Notas Etnobotánicas del Pueblo Atacameño de Socaire, C. Munizaga y H. Gunkel (Eds.). Centro de Estudios Antropológicos, Universidad de Chile. Talleres Gráficos La Nación, Santiago de Chile.

MUÑOZ, J. F. y C. A. ORTIZ. 2004. Funcionamiento hidrogeológico del acuífero del núcleo del Salar de Atacama, Chile. Ingeniería hidráulica en México XIX(3): 69-82.

No a la Junta de Vigilancia. Catarsis en la Junta de Vecinos. Chululo: http://www.chululo.cl/pages/reportajes2. php?id $=26122012 \_025016$

NOGAMI, M. 1982. Circulación atmosférica durante la última época glacial en los Andes. Norte Grande 9: 41-48. Universidad Católica de Chile, Santiago de Chile.

NÚÑEZ, L. 1992. Cultura y Conflicto en los Oasis de San Pedro de Atacama. Editorial Universitaria, Santiago de Chile.

1995. Evolución de la ocupación y organización del espacio atacameño. En Agua, ocupación del espacio y economía campesina en la región atacameña, aspectos dinámicos, P. Pourrut y L. Núñez (Eds.), pp. 78-106. Universidad Católica del Norte, Antofagasta.

NÚÑEZ, L. y T. DILLEHAY. 1992. Movilidad giratoria, armonía social $y$ desarrollo en los Andes Meridionales; Patrones de tráfico e interacción económica. Universidad Católica del Norte, Antofagasta.

ORTLIEB, L. 1995. Eventos El Niño y Episodios Lluviosos en el Desierto de Atacama: El registro de los Últimos dos Siglos. Boletín del Instituto Francés de Estudios Andinos 24: 519-537. 
ORTLOFF, C. 1981. La Ingeniería Hidráulica Chimu. En La tecnología en el mundo andino: Runakunap Kawsayninkupaq Rurasqankunaqa, H. Lechtman y A. M. Soldi (Comps.), pp. 91-134. Universidad Nacional Autónoma de México, México, D. F.

OSCHSENIUS, C. 1971. Observaciones Geoecológicas de la Puna de Atacama. Boletín Prehistoria de Chile 4: 29-58.

1973. Contribución a la Ecología y Paleoecología de la Puna de Atacama. Nuevos Antecedentes ( $2^{a}$ versión). Departamento de Geografía de la Universidad de Chile, Santiago de Chile.

1986. La Glaciación Puna Durante el Wisconsin, Desglaciación y Máximo Lacustre en la Transición Wisconsin-Holoceno y Refugios de Mega fauna Postglaciales en la Puna y Desierto de Atacama. Norte Grande 13: 29-58.

OYARZÚN O. R. 2002. Estudio de los recursos hídricos del río VilamaPuritama, II región. Tesis Ingeniería Civil. Facultad de Ciencias Físicas y Matemáticas, Universidad de Chile, Santiago de Chile.

PALERM, J. 2004. Reseña de "Rivers of Empire, Water, Aridity, And Tfe Growth of American West" de Donald Worster. Regióny Sociedad XVI(29): 181-187. Colegio de Sonora, Sonora.

PÉREZ E. 2008. Informe Tecnico de Actividades Temporada 2007-2008. Programa de Desarrollo Local PRODESAL, Municipalidad de San Pedro de Atacama, San Pedro de Atacama.

POURRUT P. y A. COVARRUBIAS. 1995. Existencia de agua en la II región de Chile: interrogantes e hipótesis. Bulletin de l'Institut Français d'Études Andines 24(3): 505-515.

POURRUT P. y L. NÚÑEZ. 1995. El Agro y la identidad atacameña: Entre la crisis y la esperanza. En Agua, ocupación del espacio y economía campesina en la región atacameña, aspectos dinámicos, P. Pourrut y L. Núñez (Eds.), pp. 107-110. Universidad Católica del Norte, Antofagasta.

PHILIPPI, R. 1860. Viaje al desierto de Atacama. Hecho de orden del Gobierno de Chile en el verano 1853-54. Librería de Eduardo Antón, Halle en Sajonia.

PHILIPPI, F. 1975. Viaje de Don Federico Phillippi por el Desierto de Atacama en 1885. Revista Chilena de Historia y Geografía 143: 171-261.

PNUMA. 2000. Perspectivas del Medio Ambiente Mundial 2000. Ediciones Mundi-Prensa, Madrid.

REDDERSEN P. 2005. Programa Aplicación de Tecnologías de Riego a Sistemas Productivos en San Pedro de Atacama, Codigo BIP 20179912-O, I.M.S.P.A.
RIVERA, F. 1995. El contexto histórico y social del manejo de los recursos agropecuarios en los oasis de San Pedro de Atacama. En Agua, ocupación del espacio y economía campesina en la región atacameña, aspectos dinámicos, P. Pourrut y L. Núñez (Eds.), pp. 61-77. Universidad Católica del Norte, Antofagasta.

ROMERO, H., A. RIVERA, P. FERNÁNDEZ. 1997. Climatología de la Puna de Atacama y su Relación con los Recursos Hídricos. En El Altiplano: Ciencia y Conciencia de los Andes: actas del II Simposio Internacional de Estudios Altiplánicos, 19 al 21 de Octubre de 1993, Arica, Chile, R. Charrier (Ed.), pp. 87-93. Universidad de Chile, Santiago de Chile.

R \& Q INGENIERÍA LIMITADA. 1995. Manejo experimental de la cuenca del río San Pedro de Atacama, II Región. Dirección General de Aguas, Ministerio de Obras Públicas, Santiago de Chile.

SALAS, J. y M. LUNA. 2013. Balance Hídrico cuencas Hidrográficas Comuna San Pedro de Atacama. Informe Técnico-Borrador para la DGA, Proyecto ProEcoServ: Project for Ecosystem Services, Modelo Conceptual, pp. 4-36.

SALAZAR, C., L. ROJAS, H. ALONSO y F. RICHASER. 2003. Geoquímica de la Cuencas Cerradas de los Salares de las Rregiones I, II y III. Dirección General de Aguas, Ministerio de Obras Públicas, Santiago de Chile.

SANTORO, C., L. NÚÑEZ, V. STANDEN, H. GONZÁLEZ, P. MARQUET y A. TORRES. 1998. La fertilización del desierto, proyectos prehispánicos de irrigación. Estudios Atacameños 16: 321-336.

SEPÚLVEDA, I. 2000. Estudio Diagnóstico de la Explotación Agropecuaria, Programa de Preinversión en Iniciativas de Desarrollo. Gente Nueva y Profesionales Consultores Ltda. Alitar, Conadi, pp. 3-12.

SEVILLA, E. 2011. Sobre los orígenes de la agroecología en el pensamiento marxista y libertario. AGRUCO-Plural, La Paz.

THOMPSON, L. G., E. MOSLEY-THOMPSON, H. BRECHER, M. DAVIS, B. LEON, D. LES, P. N. LIN, T. MASHIOTTA y K. MOUNTAIN. 2006. Abrupt tropical climate change: Past and present. Proceedings of the National Academy of Sciences 28: 536-543.

UNIVERSIDAD ARTURO PRAT, COMISIÓN NACIONAL DE RIEGO, MUNICIPALIDAD DE SAN PEDRO DE ATACAMA. 2000. Agricultura en el Desierto de la II Región de Chile. Proyecto Agrícola "San Pedro de Atacama", pp. 1-47. Departamento de Agricultura del Desierto, Universidad Arturo Prat, Calama. 
URIBE, C., V. VERELA., M. RODRIGUEZ, S. CERVANTES y C. GONZÁLEZ. 2013. Patrimonio Cultural Inmaterial de San Pedro de Atacama. http://pci.tradicionesdeatacama.cl/

URTEAGA, P. 2006. Capítulo 3: El derecho colectivo al agua. En Derechos colectivos y políticas hídricas en la región Andina, P. Urteaga (Ed.), pp. 113-158. Abya-Yala, IEP Ediciones, Lima.

VALDERRAMA, R. y C. ESCALANTE. 1988. Del tata Mallku a la mama Pacha. Riego, sociedad y ritos en los Andes peruanos. Centro de Estudios y Promoción del Desarrollo, Lima.

VAN KESSEL, J. 2000. Individuo y religión en los Andes. IECTA, Iquique.
VON TSCHUDI, J. 1966. Viaje por las Cordilleras de los Andes de Sudamérica, de Córdoba a Cobija, en el año 1858 . Boletín de la Academia Nacional de Ciencias de Córdoba 45: 115-127.

VUILLE, M. 2013. El cambio climático y los recursos hídricos en los Andes tropicales. Inter-American Development Bank, Northwest, Washington D.C.

WEISCHET, W. 1975. Las condiciones climáticas del desierto de Atacama como desierto extremo de la tierra. Norte Grande 3-4: 363-373.

YAÑEZ, N. y R. MOLINA. 2011. Las Aguas Indígenas en Chile. Observatorio Ciudadano, IWGIA, LOM, Santiago de Chile. 